ADOLFO ALVES DE VASCONCELOS

\title{
PERCEPÇÃO DE RESULTADOS EM PROJETOS SOB A PERSPECTIVA DOS FATORES CRÍTICOS DE SUCESSO
}

Dissertação apresentada à Escola Politécnica da Universidade de São Paulo para obtenção do título de Mestre em Engenharia

Área de concentração:

Engenharia de Sistemas

Orientador: Prof. Dr. José Roberto Castilho Piqueira 
FICHA CATALOGRÁFICA

Vasconcelos, Adolfo Alves de

Percepção de resultados em projetos sob a perspectiva dos fatores críticos de sucesso / A.A. de Vasconcelos. -- São Paulo, 2010.

$86 \mathrm{p}$.

Dissertação (Mestrado) - Escola Politécnica da Universidade de São Paulo. Departamento de Engenharia de Telecomunicações e Controle.

1. Administração de projetos 2 . Avaliação de projetos 3. Sistemas baseados em conhecimento I. Universidade de São Paulo. Escola Politécnica. Departamento de Engenharia de Telecomunicações e Controle II. t. 


\title{
FOLHA DE APROVAÇÃO
}

Adolfo Alves de Vasconcelos

Percepção de Resultados em Projetos sob a Perspectiva dos Fatores Críticos de Sucesso

Dissertação apresentada à Escola Politécnica da Universidade de São Paulo para obtenção do título de Mestre em Engenharia Área de concentração: Engenharia de Sistemas

Aprovado em:

\author{
Banca Examinadora
}

Prof. Dr:

Instituição:

Assinatura

Prof. Dr:

Instituição:

Assinatura

Prof. Dr:

Instituição: Assinatura 


\section{Dedicatória}

Aos meus pais que me proporcionaram os meios para poder iniciar a vida acadêmica e que tanto me apoiaram. À minha noiva Ellen que me auxiliou com seu amor, carinho e aos meus grandes amigos Carlos, Renato, Rodrigo e Gilmar que com sua amizade e diversidade de conhecimentos e experiências também contribuíram muito para a realização deste trabalho. 


\section{Agradecimentos}

Agradeço ao Prof. Dr. José Roberto Castilho Piqueira que muito mais que um orientador foi um companheiro que auxiliou com suas inteligentes críticas a elaboração deste trabalho.

Aos professores Fuad Kassab Júnior e Ricardo Paulino Marques com a perspicácia nas críticas e sugestões realizadas no exame de qualificação e que buscaram ser seguidas por realmente contribuírem no seu desenvolvimento.

À Escola Politécnica da Universidade de São Paulo que me permitiu participar de seu programa de mestrado. 


\section{Epígrafe}

"No mundo não existem tarefas difíceis, apenas a falta de determinação para realizálas."

Bodhi, o lluminado 


\section{Resumo}

As empresas enfrentam no mundo atual o fato de estarem inseridas em um ambiente cada vez mais repleto de mudanças e que acontecem numa velocidade que só tem acelerado com o passar dos anos. Nesse contexto a gestão de projetos busca contribuir para o sucesso dos projetos que tem se mostrado a fonte para que as empresas continuem e se tornem ainda mais competitivas. Com esse cenário, o trabalho em questão busca desenvolver uma ferramenta de apoio baseada na teoria dos fatores de certeza em conjunto com o desenvolvimento de uma pesquisa orientada a uma área de projetos de uma grande empresa para identificar a percepção do peso dos principais fatores críticos de sucesso e assim possibilitar aos gestores orientação no difícil caminho do sucesso em projetos. Ao final é realizada uma análise crítica dos principais resultados alcançados e sugestões para eventuais linhas de pesquisa para darem continuidade ao trabalho.

Palavras-chave: Avaliação de Projetos, Fatores Críticos de Sucesso, Fatores de Certeza, Gestão de Projetos, Sistemas Baseados em Conhecimento. 


\begin{abstract}
Companies face in today's world the fact that they are exposed to an environment increasingly filled with change and that happen at a speed that has only accelerated over the years. In this context the project management will contribute to the success of the projects that has proved the source for companies to continue and become even more competitive. With this scenario, the work in question seeks to develop a support tool based on the theory of certainty factors in conjunction with the development of a research oriented to a project area of a large company to identify the perception of the weight of the main critical success factors and thus provide guidance to managers in the difficult path to success in projects. At the end is performed a critical analysis of the main achievements and suggestions for possible lines of research in order to continue the work.
\end{abstract}

Keywords: Project Evaluation, Critical Success Factors, Certainty Factors, Project Management, Knowledge Based Systems. 


\section{Lista de Figuras}

Figura 1 - Evolução Mundial dos profissionais PMPs no mundo............................18

Figura 2 - Média percentual de sucesso em projetos - CHAOS survey..................18

Figura 3 - Média percentual de falha em projetos - CHAOS survey ........................19

Figura 4 - Média percentual de sucesso parcial em projetos - CHAOS survey ........19

Figura 5 - Áreas do conhecimento em projetos de acordo com o PMBoK ...............27

Figura 6 - Processos de Gestão de Projetos................................................ 35

Figura 7 - Fatores de Certeza no Mycin ................................................. 43

Figura 8 - Modelo para aplicação da metodologia......................................... 45

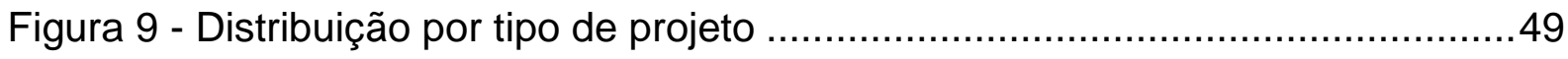

Figura 10 - Resultados ponderados da percepção da influência dos fatores críticos

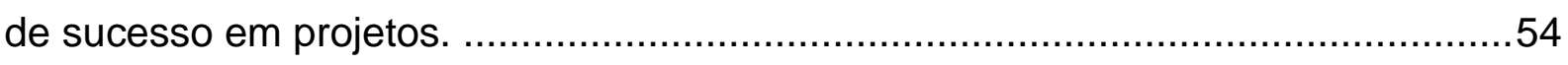

Figura 11 - Comparação dos resultados da pesquisa realizada VS Chaos Report...55 Figura 12 - Resultados da pesquisa separando as avaliações para os projetos que tiveram sucesso, daqueles que fracassaram. ...........................................56 


\section{Lista de Tabelas}

Tabela 1 - Os mitos e os novos conceitos desenvolvidos por Kerzner .34

Tabela 2 - Questionário enviado para a avaliação da percepção dos resultados em projetos

Tabela 3 - Distribuição das respostas aos questionários .50

Tabela 4 - Distribuição das respostas aos questionários dos projetos identificados como falha

Tabela 5 - Distribuição das respostas aos questionários dos projetos identificados como sucesso

Tabela 6 - Cenário fictício 1 com algumas respostas a respeito dos fatores críticos de sucesso

Tabela 7 - Cenário fictício 2 com algumas respostas a respeito dos fatores críticos de sucesso

Tabela 8 - Cenário real de avaliação de projeto de sucesso real de desenvolvimento de sistema .60

Tabela 9 - Cenário real de avaliação de projeto de fracasso de implantação de uma nova tecnologia 61

Tabela 10 - Resultados da pesquisa de campo - projetos avaliados como sucesso projetos 1 ao 3 .72

Tabela 11 - Resultados da pesquisa de campo - projetos avaliados como sucesso projetos 4 ao 6 
Tabela 12 - Resultados da pesquisa de campo - projetos avaliados como sucesso projetos 7 ao 9

Tabela 13 - Resultados da pesquisa de campo - projetos avaliados como sucesso projetos 10 ao 12

Tabela 14 - Resultados da pesquisa de campo - projetos avaliados como sucesso projetos 13 ao 15 .76

Tabela 15 - Resultados da pesquisa de campo - projetos avaliados como sucesso projetos 16 ao 18 .77

Tabela 16 - Resultados da pesquisa de campo - projetos avaliados como sucesso projetos 19 ao 21 78

Tabela 17 - Resultados da pesquisa de campo - projetos avaliados como sucesso projetos 22 ao 24 79

Tabela 18 - Resultados da pesquisa de campo - projetos avaliados como sucesso projetos 25 ao 26 .80

Tabela 19 - Resultados da pesquisa de campo - projetos avaliados como falha projetos 27 ao 29

Tabela 20 - Resultados da pesquisa de campo - projetos avaliados como falha projetos 30 ao 32

Tabela 21 - Resultados da pesquisa de campo - projetos avaliados como falha projetos 33 ao 35 .83

Tabela 22 - Resultados da pesquisa de campo - projetos avaliados como falha projetos 36 ao 38 
Tabela 23 - Resultados da pesquisa de campo - projetos avaliados como falha projetos 39 ao 41 . .85

Tabela 24 - Resultados da pesquisa de campo - projetos avaliados como sucesso projetos 42 ao 43 .86 


\section{Sumário}

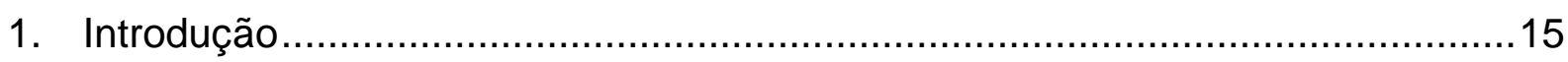

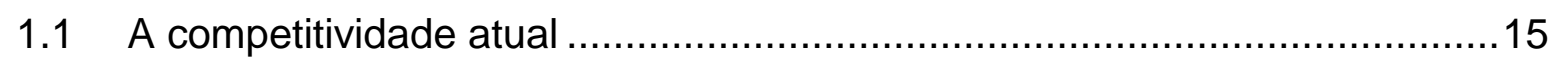

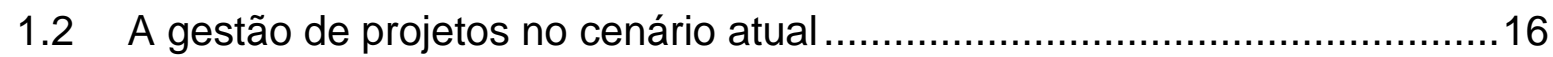

1.3 Os fatores críticos de sucessos na gestão de projetos ………..................19

1.4 Finalidades e objetivos deste estudo ..................................................20

1.5 Descrição dos Capítulos ....................................................................21

2. O contexto da Gestão de Projetos .............................................................23

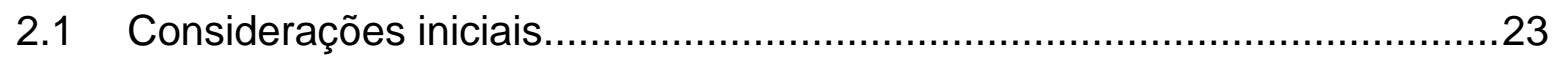

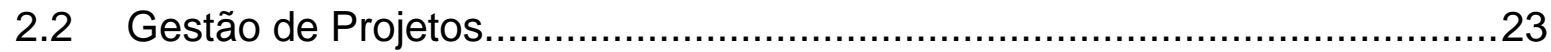

2.3 Mitos da gestão de projetos ………………........................................3

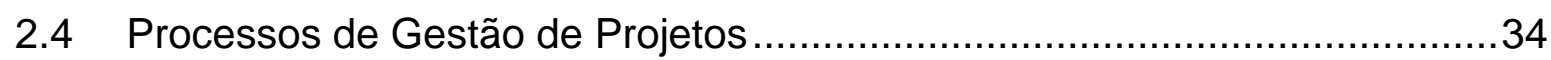

2.5 Fatores Críticos de Sucesso em Projetos .....................................................

2.6 Standish Group - Chaos Report ...........................................................

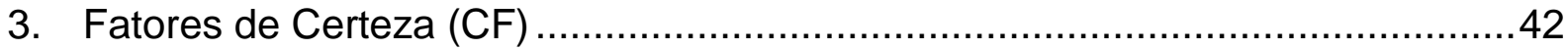

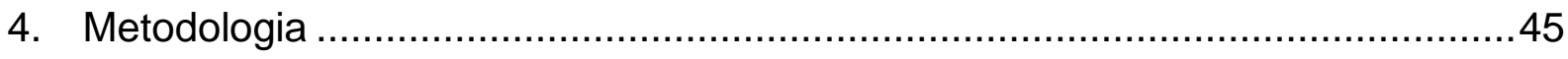

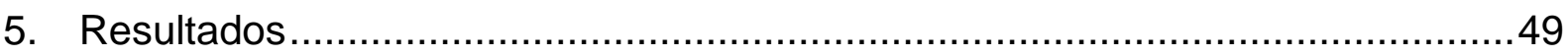

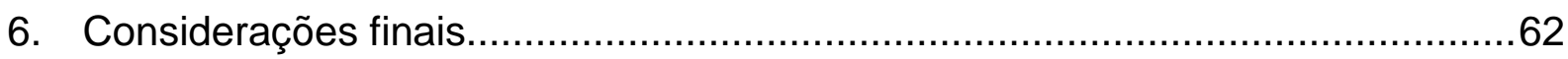

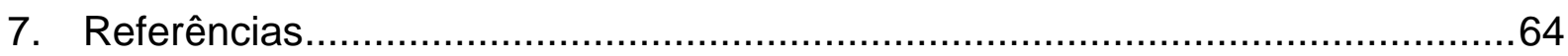

Apêndice A - Formalismo dos Fatores de Certeza (CF) ......................................68

Propagação de Fatores de Certeza (CF) ..........................................................

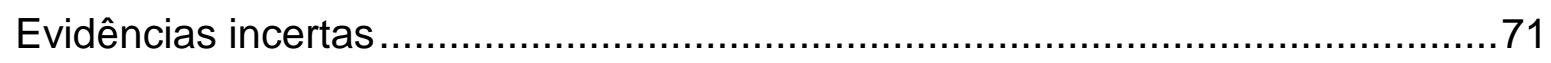


APÊNDICE B - Resultados da pesquisa de campo: projetos avaliados como sucesso.

Apêndice $C$ - Resultados da pesquisa de campo: projetos avaliados como falha......81 


\section{Introdução}

\subsection{A competitividade atual}

O mundo atual cada vez mais tem como característica a velocidade das informações e da maior facilidade em acessá-las, nesse mesmo contexto estão as empresas e seus executivos que devem utilizá-las para adotar as melhores respostas e estratégias para a boa condução de seus negócios, seja na busca por oportunidades, seja na sua criação, ainda que as informações sejam repletas de incertezas e de variáveis que não podem ser controladas. A globalização aumenta ainda mais esse cenário de incerteza no qual os efeitos em qualquer parte do mundo podem afetar sobremaneira uma empresa local. Não apenas a globalização, mas a evolução das tecnologias e as novas formas de organizações corporativas ajudam a redefinir o gerenciamento de operações que devido às novas formas de relacionamento criam arranjos complexos resultando em novas abordagens e setores industriais (Hayes et al., 2005). Lembrando Darwin, não é o mais forte que sobrevive e nem o mais inteligente, mas o que melhor se adapta às mudanças.

Nesse cenário de incerteza e alta complexidade, as organizações para se adaptar tendem a estabelecer a elaboração de uma forte postura estratégica, principalmente as pequenas e médias empresas, que não dispõe dos altos recursos de suas grandes concorrentes, sejam gigantes locais, sejam multinacionais (Knight, 2000). 
Assim, a gestão de projetos surge como uma ferramenta não apenas para facilitar o processo de gerenciamento, mas para estruturá-lo e aumentar a sustentabilidade dos negócios por meio de técnicas e práticas gerenciais consagradas em grandes empresas como IBM, NASA, governo americano, nas empresas de construção civil e, mais recentemente, nas multinacionais de tecnologia de informação e telecomunicações.

\subsection{A gestão de projetos no cenário atual}

Com o passar dos anos, a gestão de projetos tem ficado cada vez mais em evidência. Isso pode ser visto pelo crescente aumento das empresas que buscam qualificar seus executivos com esses conhecimentos e também estruturarem equipes que possam trabalhar, ainda que não estejam executando projetos, com o modo de projeto. Podemos ter uma idéia desse fenômeno observando a curva (Fig.1) de evolução do número de profissionais qualificados como PMP (Project Management Professional) por meio de certificação entregue pelo $\mathrm{PMI}^{1}$ (Project Management Institute). Um fator que parece ser decisivo para esse movimento é o aumento constante da complexidade dos projetos, além das altas taxas de falhas e de excesso de custos observados em vários estudos. Nas figuras 2, 3 e 4 temos os resultados de uma pesquisa realizada por um grupo denominado Standish Group ${ }^{2}$ e que falaremos com mais detalhes adiante. A princípio vale dizer que:

\footnotetext{
${ }^{1}$ PMI é reconhecido como uma organização de desenvolvimento de padrões pelo American National Standard Institute (ANSI) e o Guia PMBoK foi aprovado como um padrão do ANSI (ANSI/PMI 99-001-2000). O Guia PMBoK também é reconhecido como um padrão pelo Institute of Electral and Eletronic Engineers (IEEE).

${ }^{2}$ Standish Group é um grupo voltado para a pesquisa das principais causas de sucessos e falhas em projetos.
} 
- Sucesso corresponde ao projeto entregue no tempo e com custo contratados e também com todos os requisitos e funcionalidades que foram inicialmente especificados;

- Falha corresponde ao projeto cancelado ou entregue e não utilizado;

- Sucesso Parcial ${ }^{3}$ corresponde aos projetos que não foram entregues no prazo ou com o custo contratado ou que ofereçam menos funções que as especificadas;

Outros entendem que estão nas atividades não rotineiras os valores essenciais a serem agregados aos produtos / serviços que desenvolvem. Podemos dizer que o que buscam, na verdade, é algo que os ajudem a transformar idéias em que algo dê às empresas desenvolvimento de forma sustentável, considerando-se o cenário competitivo atual (Rabechini, 2005). Porém, aprender os princípios básicos na gestão de projetos e ter muitas pessoas certificadas como PMPs, não garante que a gestão está sendo utilizada na organização (Kerzner, 1999).

Cada vez mais os projetos tendem a crescer em importância para as organizações e quanto mais alinhados estiverem aos negócios das empresas, certamente, mais vantagens estas obterão na competição (KING, 1993).

\footnotetext{
${ }^{3}$ No original "Challenged"
} 


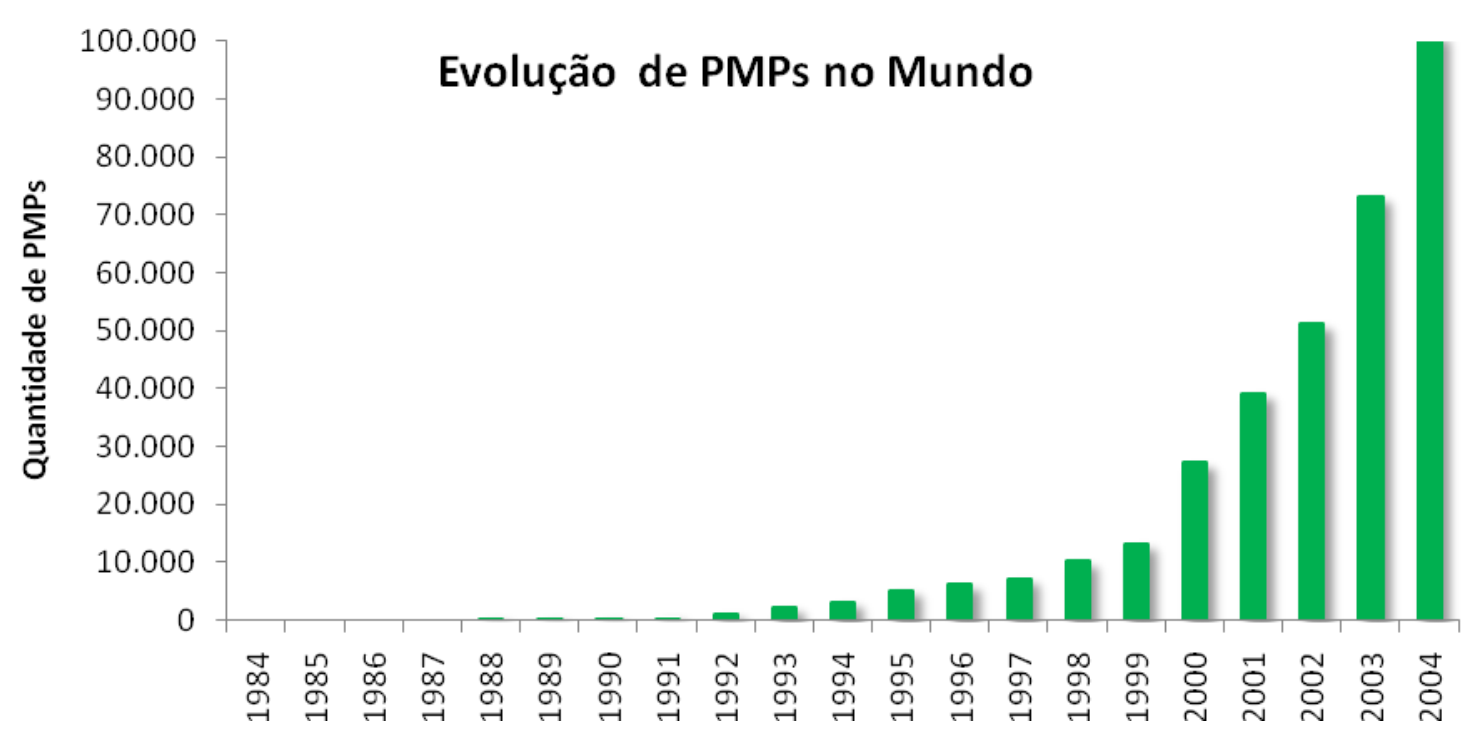

Figura 1 - Evolução Mundial dos profissionais PMPs no mundo

Média Percentual de Sucesso

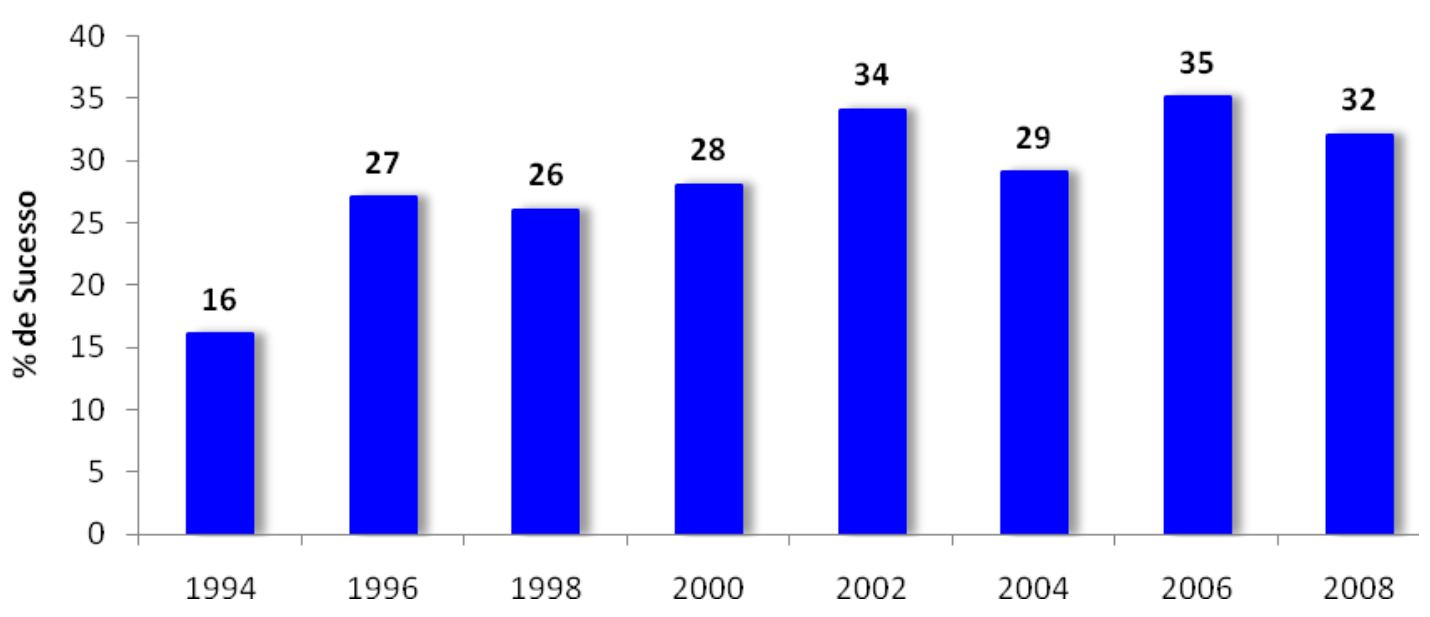

Figura 2 - Média percentual de sucesso em projetos - CHAOS survey 


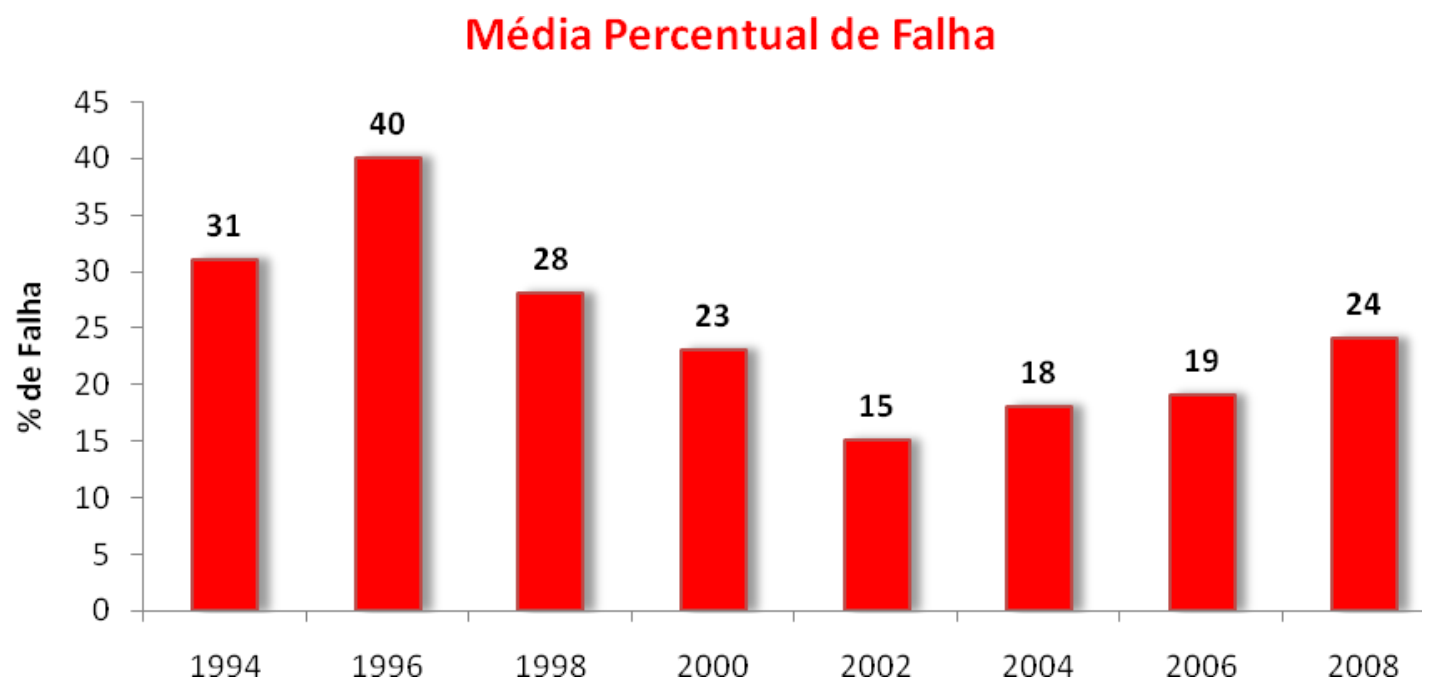

Figura 3 - Média percentual de falha em projetos - CHAOS survey
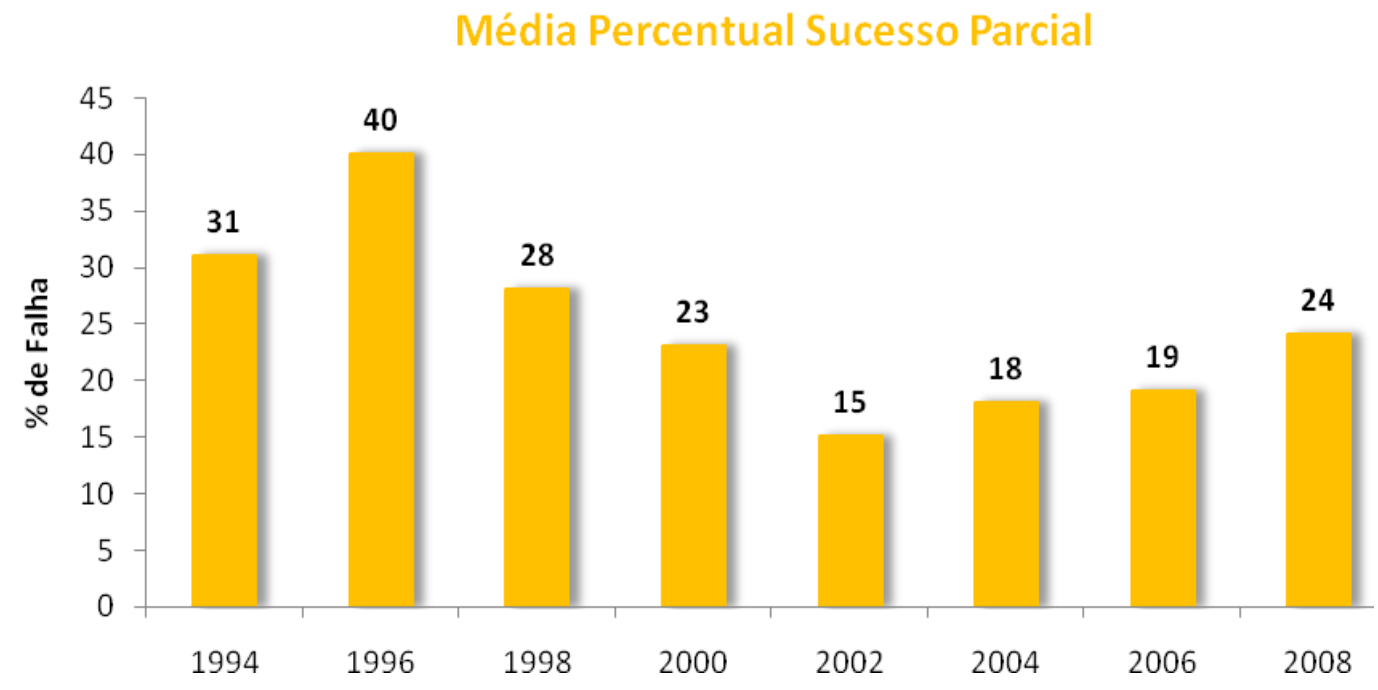

Figura 4 - Média percentual de sucesso parcial em projetos - CHAOS survey

\subsection{0s fatores críticos de sucessos na gestão de projetos}

Muitos pesquisadores têm se debruçado sobre um tema que freqüentemente aparece na forma de uma pergunta: "Quais são os fatores que mais influenciam no sucesso de projetos?" E nesse caminho, têm adotado a perspectiva de Daniel (1961) sobre a definição de fatores críticos de sucesso: 
“Fatores Críticos de Sucesso são os elementos de negócio necessários para uma empresa, produto ou projeto atingirem seu objetivo."

Os fatores críticos de sucesso são os pontos chave que definem o sucesso ou o fracasso de um objetivo definido por um planejamento de determinada organização. Estes fatores precisam ser encontrados pelo estudo sobre os próprios objetivos, derivados deles, e tomados como condições fundamentais a serem cumpridas para que a instituição sobreviva e tenha sucesso na sua área. Quando bem definidos, os fatores críticos de sucesso se tornam um ponto de referência para toda a organização em suas atividades voltadas para a sua missão. Os fatores críticos de sucesso também são fatores que definem as principais orientações que a gestão deve seguir na implantação de um verdadeiro controle sobre os processos de Gestão da Informação.

Assim, muito tem sido apresentado para buscar a definição não apenas de fatores que melhor avaliem os projetos, mas também universalizar aqueles que indicarão o fracasso do projeto se os mesmos não estiverem presentes (Dvir ET AL).

\subsection{Finalidades e objetivos deste estudo}

Este trabalho tem por finalidade investigar as variáveis que mais contribuem para o sucesso dos projetos na empresa avaliada e, por meio de pesquisa orientada, desenvolver um mecanismo que contribua para a gestão de projetos por facilitar o entendimento e também oferecer uma forma prática de utilizar a percepção dos gestores a respeito da dinâmica e das dificuldades encontradas em seu cotidiano. 
Por meio da avaliação das variáveis intituladas fatores críticos de sucesso em projeto e da aplicação dos fatores de certeza entendemos que podemos disponibilizar uma ferramenta de apoio no complexo mundo da gestão de projetos.

É importante citar que não se trata de uma receita que guiará inequivocamente para o sucesso, mas certamente permitirá ao gestor uma orientação para as ações a serem tomadas.

\subsection{Descrição dos Capítulos}

Capítulo 1 - Introdução: apresentação do escopo do trabalho e do contexto no qual o mesmo está inserido assim como uma apresentação dos conceitos iniciais que serão utilizados no seu desenvolvimento.

Capítulo 2 - Contexto da Gestão de Projetos: apresentação de um histórico e dos conceitos presentes na gestão de projetos alinhados com as teorias e o corpo de conhecimento mais respeitado entre os pesquisadores e profissionais da área chamado Project Management Body of Knowledge (PMBoK) que foi desenvolvido ao longo dos anos por um grande conjunto de estudiosos da disciplina.

Capítulo 3 - Fatores de Certeza: apresentação dos conceitos associados aos fatores de certeza e de sua utilização para possibilitar o desenvolvimento de um indicador para auxiliar o gestor na indicação do sucesso dos projetos. 
Capítulo 4 - Metodologia: apresentação da metodologia utilizada para o desenvolvimento do estudo envolvendo a elaboração da pesquisa e a apresentação do ambiente na qual a mesma foi realizada.

Capítulo 5 - Resultados: apresentação da pesquisa qualitativa realizada na obtenção da percepção dos profissionais a respeito das proposições feitas e de sua experiência na gestão de projetos.

Capítulo 6 - Considerações Finais: apresenta uma avaliação crítica do trabalho e algumas propostas para sua continuidade. 


\section{O contexto da Gestão de Projetos}

\subsection{Considerações iniciais}

A gestão de projetos é utilizada amiúde nas mais variadas empresas e instituições e seus conceitos e definições estão associados com a prática dos projetos. Para apresentar o desenvolvimento do trabalho é importante descrever as definições clássicas ligadas a esse tema.

Este capítulo objetiva apresentar as definições clássicas apresentadas pela comunidade de estudiosos e profissionais e também noções úteis para podermos avaliar o sucesso em projetos sob a perspectiva dos fatores críticos de sucesso. Entre outros assuntos poderemos responder algumas perguntas importantes como:

- O que é um projeto?

- Quais são as principais definições associadas a projetos?

- O que são fatores críticos de sucesso em projetos?

Um ponto importante a salientar é que a visão a ser apresentada é apenas um overview, dada a vastidão do tema.

\subsection{Gestão de Projetos}

Há na literatura uma extensa lista de definições a respeito do que viria a ser um projeto. Na grande maioria aparecem conceitos de unicidade e singularidade. É senso comum a definição de que um projeto é uma atividade única e que difere de 
uma atividade rotineira a qual está intrínseca a idéia de produção. É uma atividade que deve possuir um início, meio e fim bem definidos. Abaixo, apresentam-se algumas definições:

$>$ É um empreendimento temporário feito para criar um produto, serviço ou resultado único. (PMI 2004)

> É uma combinação de recursos organizacionais colocados juntos para criarem ou desenvolverem algo que não existia previamente, de modo a prover um aperfeiçoamento da capacidade de desempenho no planejamento e na realização de estratégias organizacionais. (Cleland, 1997)

$>$ É uma atividade única e exclusiva com um conjunto de resultados desejáveis em seu término. É também complexo o suficiente para necessitar de uma capacidade de coordenação específica e um controle detalhado de prazos, relacionamentos, custos e desempenho. (Meredith, 1995)

Um processo único que consiste em um grupo de atividades coordenadas e controladas com datas para início e término, empreendido para alcance de um objetivo conforme requisitos específicos, incluindo limitações de tempo, custo e recursos. (ISO 10006, 1997)

Como podemos observar, alguns conceitos são comuns às definições citadas, entre eles estão: temporalidade (prazo definido) e a singularidade (resultado único) inerente aos projetos que devem ter objetivos claramente definidos em função de um problema, de uma oportunidade ou de um interesse. O resultado de um projeto é o 
desenvolvimento da solução do problema ou o atendimento do interesse, considerando-se as restrições de tempo e recursos (MAXIMIANO, 1997).

Ainda que as definições de projeto não existissem na antiguidade, podemos verificar que as grandes construções realizadas pelo homem como o Farol de Alexandria (280 A.C), as pirâmides do Egito (2700 A.C), os Jardins Suspensos da Babilônia (600 A.C), não foram outra atividade, senão projetos bem elaborados e executados, descontando, claro, os esforços muitas vezes oriundos do grande contingente humano utilizado em suas construções, além do tempo de construção que algumas vezes atravessavam gerações, como é o caso da Muralha da China ${ }^{4}$.

A Gestão de Projetos surgiu como uma disciplina nos Estados Unidos. Seu percussor foi Henry Gantt, especialista em técnicas de planejamento e controle, que utilizou o gráfico de barra, geralmente chamado de gráfico de Gantt ${ }^{5}$, como uma ferramenta de gestão do projeto, associado às teorias do engenheiro americano Frederick Winslow Taylor considerado o pai da Administração Científica ou Taylorismo por propor o método científico na administração de empresas com foco na eficiência e eficácia operacional.

Na década de 50 iniciou-se a era moderna da gestão de projetos. Antes disso, os projetos eram controlados utilizando-se basicamente os gráficos de Gantt, técnicas

\footnotetext{
${ }^{4}$ A construção da Muralha da China iniciou-se na Dinastia Chin em 221 A.C e se estendeu até a Dinastia Ming no século XV.

${ }^{5}$ Gráfico de Gantt - gráfico de barras desenvolvido por Henry Gantt para visualizar a evolução do cronograma e das relações entre as atividades de um projeto.
} 
informais e ferramentas. Nesse tempo, dois modelos de projeto matemático foram desenvolvidos:

- Program Evaluation and Review Technique ou PERT: desenvolvido como parte do programa do míssil do submarino Polaris da marinha unida dos Estados Unidos (conjuntamente com a Lockheed Corporation ${ }^{6}$ );

- Critical Path Method (CPM): desenvolvido em conjunto por DuPont Corporation e Remington Rand Corporation para projetos de manutenção de plantas industriais. Essas técnicas matemáticas espalharam-se rapidamente em muitas empresas.

Enquanto PERT é o cálculo a partir da média ponderada de três durações possíveis de uma atividade (otimista, mais provável e pessimista), CPM é um método de apuração do caminho crítico dada uma seqüência de atividades, isto é, quais atividades de uma seqüência não podem sofrer alteração de duração sem que isso reflita na duração total de um projeto.

Em 1969, o Project Management Institute (PMI) iniciou o desenvolvimento de uma metodologia de gerenciamento para servir aos interesses das mais diversas empresas, da indústria de software à de construção.

\footnotetext{
${ }^{6}$ A Lockheed Corporation foi uma companhia aeroespacial norte-americana. Entre seus famosos aviões está o caça invisível, o F-117 Nighthawk.
} 
Em 1981, os diretores do PMI autorizaram o desenvolvimento de um guia de projetos, o Project Management Body of Knowledge (PMBoK), contendo os padrões e as linhas mestras das práticas que passaram a ser amplamente utilizadas. Esse modelo identifica as boas práticas em gestão de projetos dentro de nove áreas de conhecimento, conforme a figura 5 abaixo:

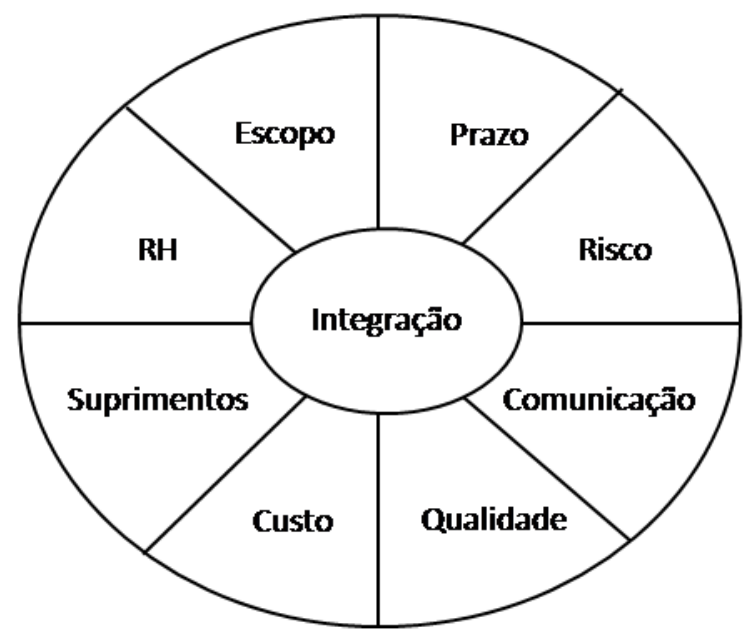

Figura 5 - Áreas do conhecimento em projetos de acordo com o PMBoK

Integração: identifica os processos necessários para assegurar que todos os elementos do projeto sejam adequadamente coordenados. Os processos considerados pelo PMI (2004) são:

- Project charter: documento que formaliza o início de um projeto;

- Declaração do escopo do projeto (preliminar): uma declaração preliminar com o escopo do projeto a ser desenvolvido;

- Plano de Gerenciamento do Projeto: estabelece as ações e condições necessárias para definir, preparar, integrar e coordenar os planos que sustentarão a gestão do projeto; 
- Direcionamento e gerenciamento da execução do projeto: executar o plano de gerenciamento do projeto;

- Controle integrado das alterações;

- Encerramento do projeto: organizar a documentação do fechamento do projeto.

Escopo: área que identifica os processos necessários para que estejam contempladas no projeto apenas as atividades referentes a ele nos termos de suas metas e objetivos por meio do desenvolvimento conceitual, completa definição e execução para que seja finalizado com sucesso. Os processos considerados pelo PMI (2004) são:

- Planejamento do Escopo: criação do plano de gestão de escopo do projeto que visa explicar como será definido, verificado e controlado o escopo do projeto;

- Definição do Escopo: desenvolve uma declaração detalhada do escopo do projeto como base para as futuras decisões do projeto;

- Criação da Work Breakdown Structure (WBS): subdivisão das entregas e trabalho do projeto em componentes menores, com melhor possibilidade de gestão;

- Verificação do Escopo: aceitação formal do escopo do projeto;

- Controle das Alterações do Escopo 
Prazo: identifica os processos necessários para a conclusão do projeto no tempo previsto. Os processos considerados pelo PMI (2004) são:

○ Definição das atividades: identificação das atividades que devem ser elaboradas para as entregas identificadas na WBS;

○ Seqüência das atividades: identificação e documentação das dependências entre as atividades do projeto;

- Estimativa dos recursos das atividades: identifica os recursos necessários para cada uma das atividades;

- Estimativa da duração das atividades: identificar o tempo a ser dispêndio em cada uma das atividades;

- Desenvolvimento do Cronograma: identifica a seqüência das atividades, duração e os recursos necessários para a sua realização;

- Controle do Cronograma: identifica e controla as mudanças no cronograma do projeto e os respectivos impactos para as suas entregas.

Custo: identifica os processos necessários para assegurar que o projeto seja concluído de acordo com o orçamento previsto. Os processos considerados pelo PMI (2004) são:

- Estimativa dos custos: estima os custos envolvidos na execução das atividades do projeto; 
- Orçamentação dos custos: para fins de controle contábil do projeto e para uma posterior análise financeira, é necessário controlar o valor agregado de todas as estimativas de custos;

- Controle dos custos: possibilitar tomadas de decisão de acordo com o andamento do projeto e os custos efetivados;

Qualidade: identifica os processos necessários para garantir que os produtos ou serviços do projeto sejam entregues de acordo com as especificações realizadas. Os processos considerados pelo PMI (2004) são:

- Planejamento da qualidade: identificar quais as necessidades de qualidade do projeto para atendê-las;

- Garantia da qualidade: atuar no projeto por meio das atividades relacionadas à área de qualidade para permitir que o mesmo esteja em conformidade com o esperado pelos envolvidos;

- Controle da qualidade: monitorar o projeto para identificar se as atividades estão dentro do padrão de qualidade esperado e também para combater as possíveis causas de desempenho insatisfatório.

Risco: identifica os processos relacionados à identificação, análise e respostas aos riscos dos projetos. Os processos considerados pelo $\mathrm{PMI}$ (2004) são:

- Planejamento da Gestão do Risco: como realizar a gestão do risco; 
- Identificação dos Riscos: apontar os riscos que podem afetar o projeto;

- Análise Qualitativa e Quantitativa dos Riscos: analisar os riscos por meio de seu impacto no projeto para auxiliar na proposta de planos de ações;

- Planejamento das Respostas aos Riscos: definir os planos de ações para mitigar os riscos;

- Monitoração e Controle dos Riscos: permitir o controle e as tomadas de ações por meio da efetiva identificação da evolução e dos impactos dos mesmos no projeto.

Comunicação: identifica os processos relacionados à obtenção, geração e disseminação da informação adequada para todos os envolvidos no projeto. Os processos considerados pelo PMI (2004) são:

- Planejamento das Comunicações: identifica as informações necessárias para serem distribuídas incluindo a freqüência que isso ocorrerá;

- Distribuição de informações: define como as informações serão entregues aos interessados;

- Relato de Desempenho: prospecta, define e distribui as informações de desempenho do projeto;

- Gestão dos interessados: define e gere as informações que serão disponibilizadas aos diversos interessados no projeto. 
Recursos humanos: identifica os processos relacionados à gestão efetiva do pessoal envolvido no projeto. Os processos considerados pelo PMI (2004) são:

- Planejamento organizacional: define as responsabilidades e funções dos envolvidos no projeto;

- Formação de equipe: define as pessoas necessárias para o desenvolvimento do projeto;

- Desenvolvimento de equipe: desenvolve os conhecimentos e habilidades necessárias nas equipes de projetos;

- Administração de equipes: administra as equipes de acordo com o desempenho e as competências adquiridas e necessárias para o bom andamento dos projetos;

Aquisição: identifica os processos necessários para aquisição de bens e serviços para a efetivação dos projetos. Os processos considerados pelo PMI (2004) são:

- Planejamento das aquisições: define as necessidades do projeto com relação aos bens e serviços a serem adquiridos e 0 cronograma de aquisição;

- Planejamento das solicitações: define os requisitos dos bens e serviços que serão adquiridos, assim como mapeia e analisa os fornecedores;

- Solicitação: prospecção de informações de custos e também levantamento junto aos fornecedores de propostas comerciais; 
- Seleção das fontes: escolha dos fornecedores por meio da composição e análise obtidos nos itens citados anteriormente;

- Administração de contratos: gestão dos fornecedores;

- Encerramento do contrato: finaliza o contrato juntamente com os itens e anexos inerentes aos mesmos.

Para cada um desses itens há um detalhamento minucioso das práticas a serem adotadas no desenvolvimento de um projeto, o que não deve ser seguido fidedignamente, mas sim adaptado para o contexto da empresa que muitas vezes não necessita de todos os controles e ferramentas sugeridas para implantação. O mais importante desse modelo é promover um vocabulário comum entre os seus diversos "stakeholders" para o desenvolvimento constante da gestão de projetos.

\subsection{Mitos da gestão de projetos}

Com o aumento do conhecimento e da utilização dos conceitos associados à gestão de projetos, estão perdendo força alguns mitos criados e disseminados que corroboravam com a idéia de que o incentivo à prática e desenvolvimento de equipes voltadas para essa atividade pudessem agregar valor às empresas. A seguir apresentamos a compilação de uma proposta de Kerzner (1998) para a evolução desses pré-conceitos a respeito de projetos.

\footnotetext{
${ }^{7}$ Stakeholders: são todos os envolvidos no projeto como fornecedores, clientes, patrocinadores, etc.
} 
Mitos

Aumento de pessoas e custos

O controle pode aumentar os custos e reduzir a lucratividade

Aumenta as alterações no escopo

Cria instabilidade organizacional e aumenta os conflitos entre as áreas da organização

Cria problemas

Só grandes projetos necessitam de gestão de projetos

Pode diminuir a competitividade da empresa

\section{Conceitos revisados}

Otimização do trabalho que produzir mais, com menos pessoas

O controle aperfeiçoa o trabalho e permite aumentar a lucratividade

Permite maior controle sobre as alterações de escopo

Torna a organização mais eficiente e melhora a relação e a comunicação entre as áreas

Possibilita a solução eficaz de problemas

Todos os projetos se beneficiam da gestão de projetos

Possibilita que a empresa e seus negócios evoluam e se tornem mais competitivos

Tabela 1 - Os mitos e os novos conceitos desenvolvidos por Kerzner

\subsection{Processos de Gestão de Projetos}

De acordo com a ABNT (2000) o processo de gestão de projetos é:

Um grupo de recursos e atividades inter-relacionadas que transformam insumos em resultados. Os processos do projeto incluem os processos de gestão do projeto. Os recursos podem incluir gerenciamento, serviços, pessoal, finanças, utilidades, equipamentos, técnicas e métodos.

Conforme o PMoK (2004) há cinco processos de gestão de projetos de acordo com a figura abaixo: 


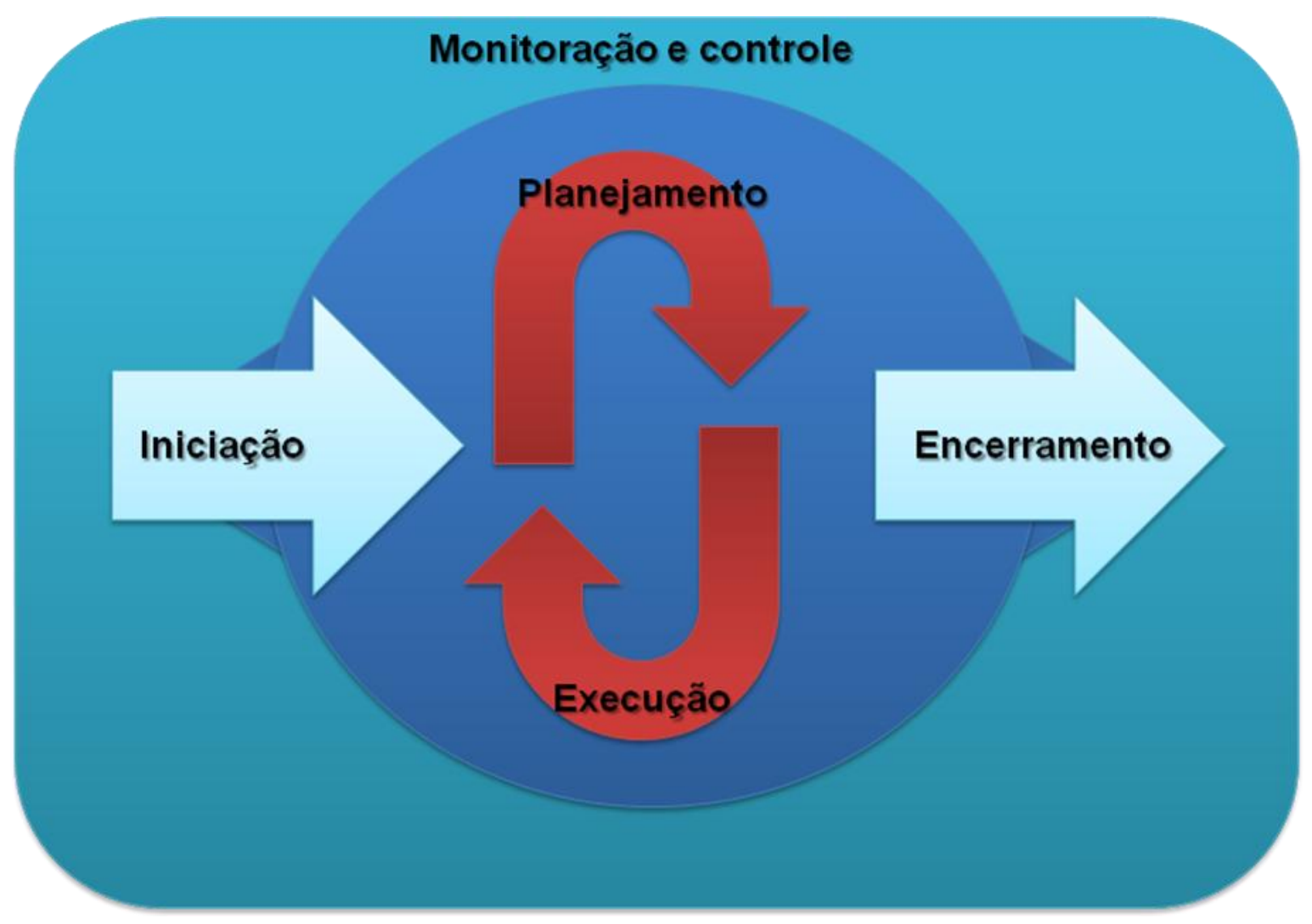

Figura 6 - Processos de Gestão de Projetos

1. Iniciação: autorização do projeto ou fase;

2. Planejamento: são processos iterativos de definição e refinamento de objetivos e seleção dos melhores caminhos para atingir os objetivos;

3. Execução: execução dos planos do projeto: coordenação de pessoas e outros recursos para executar o plano;

4. Monitoramento e Controle: medição e monitoramento do desempenho do projeto. Garantem que os objetivos do projeto são alcançados através do monitoramento e medição regular do progresso, de modo que ações corretivas possam ser tomadas quando necessário;

5. Encerramento: formaliza a aceitação do projeto ou fase para a sua finalização. 
Como representado na figura 6 , os grupos de processo são ligados pelos resultados que produzem: o resultado de um processo freqüentemente é a entrada de outro. Os cinco grupos de processos possuem conjuntos de ações que levam o projeto adiante, em direção ao seu término.

Dentro dos cinco grupos de processos existem duas categorias de processos: básicos e facilitadores. Os processos básicos possuem uma ordem lógica e seguem uma progressão rígida. Os processos facilitadores são mais flexíveis, e dão suporte aos processos básicos.

As atividades no caminho crítico são monitoradas ativamente quanto a deslizes, enquanto os deslizes nas atividades do caminho não crítico são verificados periodicamente.

Repetir os processos de iniciação antes da execução de cada fase é uma maneira de se avaliar se o projeto continua cumprindo as necessidades de negócio. Envolver as partes interessadas no projeto em cada uma das fases é uma maneira de aumentar as probabilidades de satisfação dos requisitos do cliente, além de servir para fazê-los sentirem-se envolvidos no projeto - o que muitas vezes é essencial para o sucesso do mesmo.

A monitoração e comunicação do desempenho do projeto são responsabilidades do gestor de projetos. É necessária a verificação dos resultados para que ações de correção sejam realizadas e possam permitir que o projeto esteja alinhado com as linhas de base de custo, prazo e escopo. Conforme veremos a seguir, a 
comunicação do projeto é um dos principais elementos para que a gestão de projetos bem sucedida.

\subsection{Fatores Críticos de Sucesso em Projetos}

O conceito de sucesso em projetos tem sido objeto de grande discussão na atualidade. Judgev e Müller (2005) apresentam uma retrospectiva com uma visão acerca do sucesso em projetos que tem mudado com o passar dos anos, desde definições limitadas à fase de implantação do ciclo de vida de projetos para definições que refletem uma avaliação do sucesso através de todo o ciclo de vida do projeto e do produto. Em seu artigo, avaliam a evolução acerca do sucesso em projetos nos últimos 40 anos e discutem condições para o sucesso, fatores críticos de sucesso e cenários de sucesso. O grau de resultado de um projeto pode ser verificado ao se avaliar se os objetivos foram alcançados. Outras características de um projeto que merecem destaque são a incerteza e a complexidade inerentes, pois muitas vezes se parte de um problema no presente para desenvolver uma solução desconhecida no futuro. Quanto maior o grau de desconhecimento, maior a incerteza e o risco envolvidos. A elaboração progressiva que caracteriza um projeto geralmente torna o escopo descrito no início cada vez mais explícito e detalhado, à medida que o projeto se desenvolve, gerando uma maior compreensão de seus objetivos. Devido a estas características, projetos são diferentes de atividades regulares, e demandam, portanto, tratamento diferenciado com relação ao seu gerenciamento, técnicas, ferramentas e habilidades (CARVALHO, 2005). 
Fortune e White (2006) apresentam uma revisão bibliográfica abrangente, na qual tabulam os principais fatores críticos de sucesso em projetos mais citados na literatura por meio de uma pesquisa em 63 artigos e os relaciona de acordo com a freqüência que os mesmos aparecem nos artigos, conforme listado abaixo:

- Apoio da gerência sênior

- Objetivos claros e realistas

- Planejamento firme e detalhado mantido atualizado

- Boa comunicação e feedback

- Envolvimento do cliente/usuário

- Equipe qualificada / suficiente staff

- Gestão da mudança eficaz

- Gerente de projeto competente

- Boa base em projetos

- Recursos suficientes e bem alocados

- Boa liderança

- Tecnologia comprovada e familiar

- Cronograma realista

- Riscos identificados e gerenciados

- Patrocinador de projeto

- Controle/monitoramento eficaz

- Orçamento adequado

- Cultura organizacional 
- Bom desempenho de consultores externos

- Planejamento para encerramento/revisão

- Provisão para treinamento

- Estabilidade política

- Seleção adequada e experiência com metodologia e ferramentas de gestão de projetos

- Influências do ambiente

É importante citar que nessa análise foi identificado que pelo menos um dos três primeiros fatores críticos de sucesso (apoio da gerência sênior, objetivos claros e realistas e planejamento firme e detalhado mantido atualizado) apareceu em $87 \%$ dos artigos avaliados, enquanto que os três juntos apareceram em apenas $17 \%$ deles. Isso indica a grande heterogeneidade presente não apenas nos projetos, mas também nas organizações e nos ambientes que os mesmos estão inseridos.

Um ponto relevante a ser levantado é que, nessas avaliações, não há uma análise de como se dá o inter-relacionamento dos fatores críticos de sucesso. Por exemplo, como a cultura da empresa ou a estabilidade política influenciam o apoio da alta gerência e vice-versa.

Outros autores também têm o propósito de avaliar os fatores críticos de sucesso ou falha na gestão de projetos e examinar as relações entre estes fatores e variáveis de fundo organizacional. Pode-se citar o trabalho de Hyväri (2006), que tem o objetivo de obter uma compreensão de como clientes de projetos e patrocinadores 
apresentam suas necessidades e expectativas para assegurar o sucesso em projetos. Por meio de um survey respondido por gerentes de projeto de diversos setores, foi obtida uma lista de fatores críticos relacionados ao projeto, ao gerente de projeto, aos membros das equipes, à organização e ao ambiente.

A importância de aspectos relacionados às pessoas envolvidas no projeto também tem sido foco de crescente interesse, salientando-se fatores como a adequação da personalidade do gerente e seu estilo de liderança ao tipo de projeto (DVIR, SADEH e MALACH-PINES, 2006; TURNER e MÜLLER, 2005).

\subsection{Standish Group - Chaos Report}

O Standish Group foi criado em 1985 com o objetivo de coletar informações sobre as falhas e sucessos de projetos em ambientes de TI para desenvolver pesquisas e análises orientadas na busca por alternativas que permitissem aumentar o sucesso em projetos e prevenir as causas mais comuns de suas falhas.

Ao longo dos anos foram publicados diversos resultados de suas pesquisas que envolvem a análise de mais de 50.000 projetos em todo o mundo. Os projetos considerados em questão envolvem apenas organizações governamentais e comerciais, excetuando consultorias, vendedores e fornecedores. Isso exclui de sua lista, por exemplo, a Microsoft que atua em grande parte como consultoria e fornecedora de soluções. 
A primeira pesquisa realizada em 1994 foi feita por meio do envio de emails com questionários e que resultou na avaliação de mais de 8.000 projetos de desenvolvimento de aplicações. A metodologia atual da empresa é coletar informações por meio de uma base de respondentes formada por profissionais e executivos de empresas que recebem uma quantia por cada questionário respondido e que conta atualmente com aproximadamente 3.000 membros ativos. Os critérios para que essas pessoas respondam aos questionários são que:

- Devem ter acesso a alguns dados dos projetos;

- Já devem ter aplicações em operação;

- Devem possuir plataformas particulares em operação.

A pesquisa denominada Chaos Report apresenta as taxas de sucesso, falha e de projetos que não atingiram plenamente seus objetivos dentro dos critérios clássicos: custo, prazo e escopo. O resultado dessa pesquisa clarificou aos profissionais e pesquisadores em gestão de projetos a grande necessidade de desenvolver a disciplina e disseminá-la a fim de garantir uma maior eficácia no desenvolvimento dos projetos. Além disso, a pesquisa identifica alguns pontos adicionais que ajudam a entender quais as características dos projetos que podem ajudá-los a apresentar maiores taxas de sucesso. Um exemplo é o tamanho do projeto. Foi identificado que $61 \%$ dos projetos com custos inferiores a US $\$ 750$ mil tiveram sucesso, enquanto apenas $19 \%$ dos projetos entre US\$750 mil e US\$3 milhões obtiveram o mesmo resultado. 


\section{Fatores de Certeza (CF)}

A incerteza pode ser considerada como a falta de informação adequada para tomar uma decisão. O tratamento de incertezas é uma das mais importantes capacidades dos peritos humanos. Não é possível pensar um problema econômico como se fosse um simples projeto de engenharia monetária, uma vez que projetos econômicos são, via de regra, sociais e qualquer política social, técnica e moralmente adequada, deve considerar a multidisciplinaridade da questão (Piqueira, 2000).

Entre os grandes desafios encontrados em qualquer modelagem que envolva variáveis humanas, encontramos as incertezas inerentes a todo e qualquer processo, o que é ainda mais verdadeiro na maioria absoluta dos projetos. Entre os tipos de incertezas temos:

- Conhecimento incerto: freqüentemente o perito possui somente conhecimento heurístico sobre alguns aspectos do domínio. Exemplo: Um mecânico de automóvel experiente que por meio de um ruído do motor sabe com certa certeza a peça a ser trocada, porém, algumas vezes, não sabe o porquê do problema;

- Dado incerto: mesmo quando se está seguro do conhecimento sobre certo aspecto do domínio, pode haver incerteza nos dados que descrevem o ambiente externo. Exemplo: Cronograma de um projeto;

- Informação incompleta: freqüentemente é necessário tomar decisões baseadas em informação incompleta. Exemplo: A compra de ações motivada por uma alteração drástica em um segmento da economia. 
Nesse contexto, um modelo para o tratamento de incertezas fornece maneiras de expressar incertezas associadas a hipóteses, bem como maneiras de combinar várias incertezas em uma única. Na literatura podem ser encontradas diferentes abordagens que viabilizam o raciocínio incerto, geralmente propostas como alternativas ao raciocínio probabilístico. Tais propostas são muitas vezes baseadas na dificuldade em se obter uma quantidade suficiente de dados para se avaliar de modo consistente os problemas abordados.

Fatores de certeza representam a confiança que se tem em uma evidência. Existem diferentes maneiras de se representar fatores de certeza. A figura abaixo mostra a confiança representada por fatores de certeza usada no MYCIN [Harmon 85].

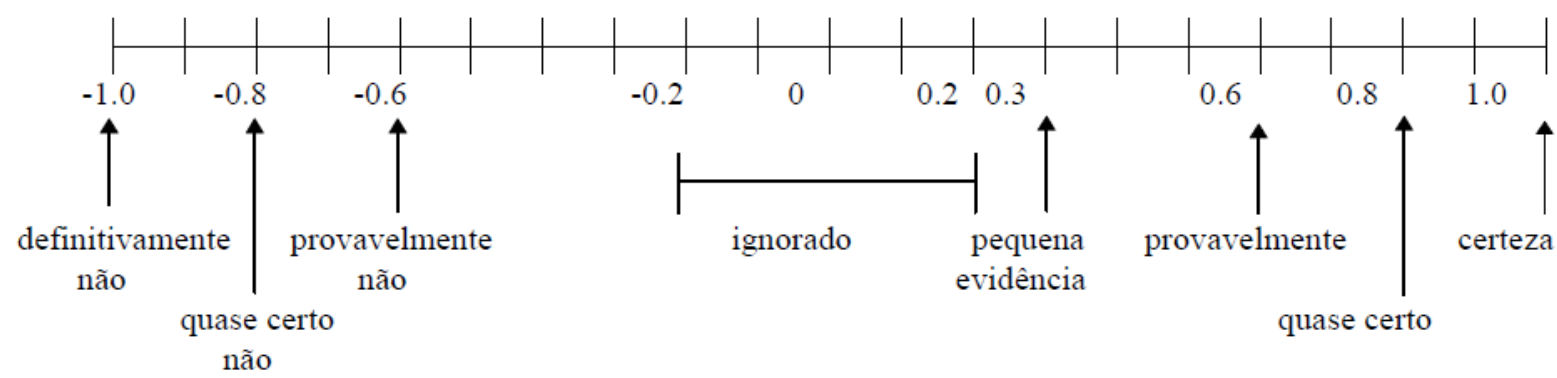

Figura 7 - Fatores de Certeza no Mycin

Os números variam entre -1 que indica evidência definitiva de que o fato é falso e +1 que indica que o fato é definitivamente verdade. Fatores de certeza não são probabilidades, são medidas informais de confiança ou certeza com relação a 
uma evidência. Eles representam o grau de crença de que a evidência é, de fato, verdade.

$\mathrm{Na}$ elaboração do trabalho em questão, os fatores de certeza são utilizados na construção do sistema por se tratar de uma abordagem com sucesso em sistemas baseados em conhecimento. A sua formalização encontra-se como anexo no Apêndice A. 


\section{Metodologia}

O presente estudo é baseado na avaliação da percepção da influência dos fatores críticos de sucesso em projetos das pessoas envolvidas na execução e gestão de projetos e na utilização da teoria de fatores de certeza para uma avaliação do conhecimento apreendido. Para tal utilizou-se o conceito mostrado na figura a seguir.

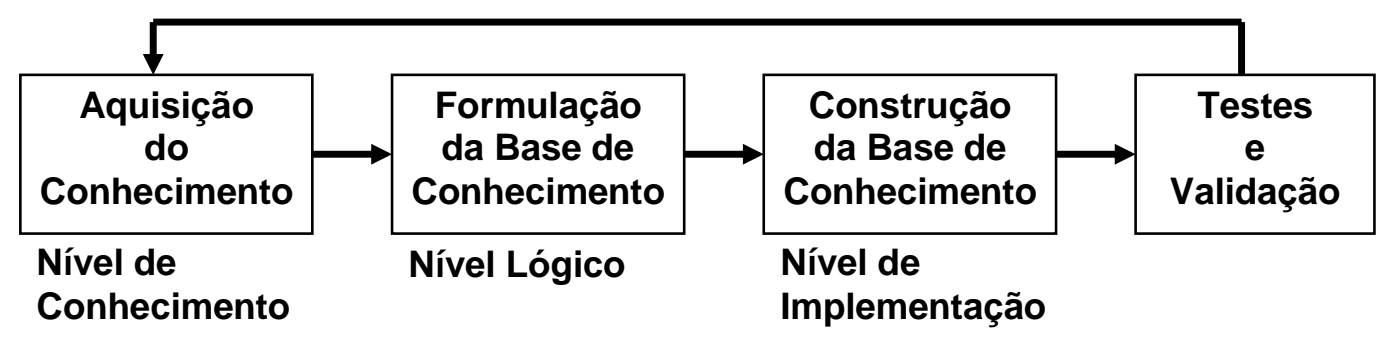

Figura 8 - Modelo para aplicação da metodologia.

Utilizou-se um questionário para a aquisição do conhecimento em linha com o questionário utilizado pelo Standish Group para a obtenção das informações referentes aos fatores críticos de sucessos em projetos. O questionário foi aplicado em uma área de projetos de uma empresa de grande porte do setor financeiro brasileiro e que nos últimos anos tem sofrido grandes mudanças, não apenas pelas fusões e aquisições pelas quais passou, mas também por uma estratégia organizacional de desenvolver a cultura de projetos. Os questionários foram enviados para 40 pessoas, das quais 30 retornaram, resultando em um total de 43 projetos avaliados (Apêndice B e C). 
A área avaliada é composta por aproximadamente 2.000 pessoas, grande parte das quais cuidam da operação do negócio, porém os avaliados são responsáveis pela condução de projetos, tanto no que diz respeito à melhoria de processos, quanto à avaliação e implantação de novas tecnologias. A amostra, apesar de pequena absolutamente, tem grande peso relativo na área avaliada dado que há uma equipe de aproximadamente 50 pessoas trabalhando na maior parte de seu tempo com a gestão de projetos.

Na tabela a seguir apresentamos o questionário enviado em um exemplo já preenchido. Foi feita uma explicação do contexto e do intuito da pesquisa, além de uma orientação na forma de preenchimento dos questionários, foram passadas detalhadamente as informações referentes aos fatores críticos de sucesso e também os critérios a serem utilizados para responder ao questionário. Conforme detalhado a seguir.

\begin{tabular}{|l||c|c|c|c|c|}
\hline \multicolumn{1}{|c|}{ Alternativas } & \multicolumn{3}{c|}{ Projetos } \\
\hline TIPO DO PROJETO & Software & Hardware & & \\
\hline SUCESSO ou FALHA & Sucesso & Sucesso & & \\
\hline a. Objetivos claros e realistas & Muito Alto & Alto & & \\
\hline b. Apoio da alta gerência & Alto & Muito Alto & & \\
\hline c. Gestor de projetos competente & Moderado & Baixo & & \\
\hline d. Equipe qualificada & Moderado & Alto & & \\
\hline e. Recursos suficientes & Alto & Alto & & \\
\hline f. Planejamento & Alto & Alto & & \\
\hline g. Boa comunicação & Moderado & Alto & & \\
\hline h. Envolvimento do cliente & Alto & Muito Alto & & & \\
\hline i. Orçamento adequado & Baixo & Baixo & & \\
\hline j. Complexidade do projeto & Baixo & Muito Baixo & & \\
\hline k. Controle/ Monitoramento Efetivo & Alto & Alto & & & \\
\hline
\end{tabular}

Tabela 2 - Questionário enviado para a avaliação da percepção dos resultados em projetos 
Critérios:

- Seleção do tipo do projeto considerado:

- Software: projetos que envolvam puramente o desenvolvimento de software. Exemplo: desenvolvimento de sistema de gestão de projetos;

- Hardware: projetos que envolvam o desenvolvimento de equipamentos ou dispositivos ou ainda a sua implantação no ambiente da empresa. Exemplo: substituição do parque de equipamentos de uma empresa;

- Processo: projetos que envolvessem adequações ou alteração de processos. Exemplo: reestruturação do fluxo das atividades necessárias para o cadastro de um novo cliente;

- Misto: projetos que envolvessem dois ou mais elementos dos tipos citados anteriormente, por exemplo, implantação da digitalização no ambiente corporativo para eliminação de papéis e também para a otimização dos processos internos da empresa. Nesse caso, provavelmente seria necessária a reorganização das atividades utilizadas para o arquivamento de documentos, o desenvolvimento de software específico para gerenciar os documentos digitalizados e provavelmente a implantação de equipamentos que possibilitassem a digitalização dos documentos como scanners ou multifuncionais.

- Seleção do sucesso ou falha do projeto:

- Sucesso: para avaliar um projeto como sucesso foi sugerida o pleno alcance quanto ao prazo, custo e escopo do mesmo; 
- Falha: caso o projeto não tivesse obtido êxito em um dos itens definidos acima dentro de uma tolerância de 5\%.

- Seleção do impacto do fator crítico de sucesso para o sucesso ou fracasso do projeto:

- Para o caso de avaliar um projeto de sucesso, preencher o quanto a presença do fator crítico de sucesso contribuiu para o seu desempenho;

- Para o caso de avaliar um projeto de fracasso, preencher o quanto a ausência do fator crítico de sucesso contribuiu para o seu desempenho. 


\section{Resultados}

Para a utilização dos dados da pesquisa (Apêndice $A$ e $B$ ) foi desenvolvido um banco de dados relacional baseado na idéia da figura 8. Apesar de terem sido colhidas as informações referentes ao tipo de projeto, isso não foi utilizado, devido à pequena amostra. Abaixo se mostra a distribuição pelo tipo dos projetos a fim de permitir um maior conhecimento a respeito dos resultados obtidos.

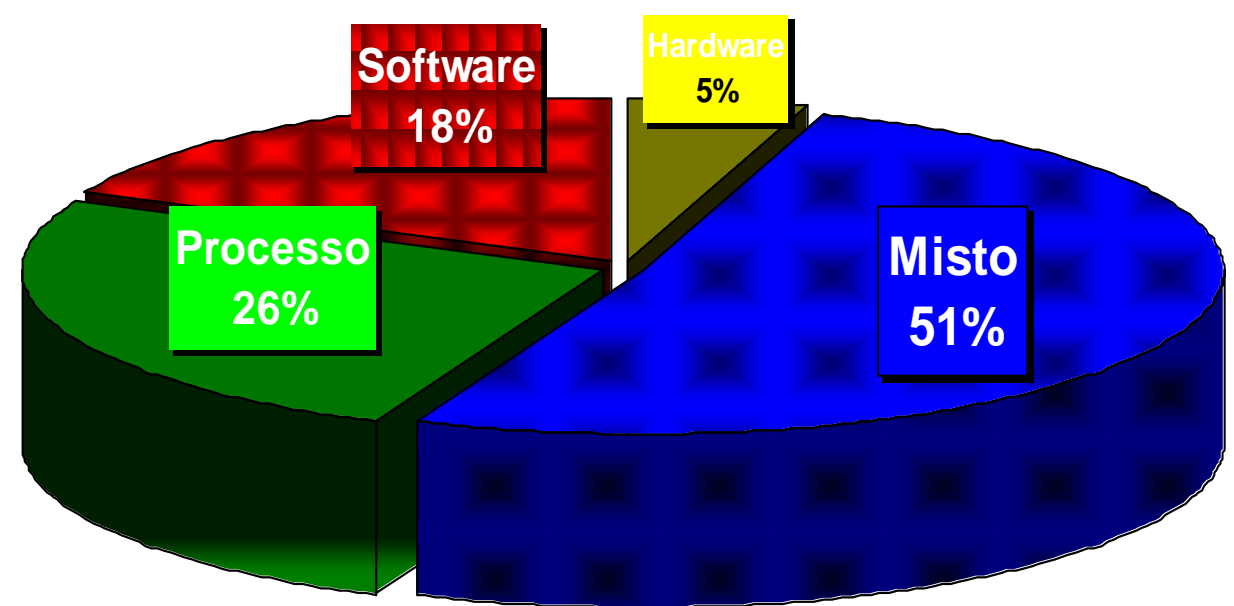

Figura 9 - Distribuição por tipo de projeto

Como pode ser observado, há uma grande dispersão entre os tipos de projetos e também uma pequena participação daqueles definidos como projetos de hardware. Essa distribuição mostra que há uma grande interação entre os diversos setores da empresa no desenvolvimento dos projetos dado o resultado de $51 \%$ dos projetos definidos como mistos. 
Na tabela 3, mostramos a distribuição das respostas aos questionários o que nos mostra algumas informações interessantes:

- Os avaliados responderam apenas em 14\% (6) dos projetos que um fator crítico de sucesso não teve nenhuma influência;

- Orçamento adequado é o fator crítico de sucesso que tem menor importância para o sucesso de projeto considerando que 49\% das respostas indicaram que o seu impacto foi "Nenhum", "Muito Baixo" ou "Moderado";

- "Objetivos Claros e Realistas" e "Recursos Suficientes" são os fatores críticos de sucesso de maior importância considerando que $88 \%$ das respostas indicaram que o seu impacto foi "Moderado", "Alto" ou "Muito Alto";

\begin{tabular}{lcccccc} 
Fatores Críticos de Sucesso & Nenhum & Muito Baixo & Baixo & Moderado & Alto & Muito Alto \\
Apoio da alta gerência & $0 \%$ & $16 \%$ & $5 \%$ & $35 \%$ & $21 \%$ & $23 \%$ \\
Boa comunicação & $0 \%$ & $12 \%$ & $7 \%$ & $26 \%$ & $26 \%$ & $30 \%$ \\
Complexidade do projeto & $0 \%$ & $5 \%$ & $16 \%$ & $42 \%$ & $26 \%$ & $12 \%$ \\
Controle/ Monitoramento Efetivo & $0 \%$ & $5 \%$ & $14 \%$ & $35 \%$ & $30 \%$ & $16 \%$ \\
\hline Envolvimento do cliente & $0 \%$ & $7 \%$ & $12 \%$ & $23 \%$ & $30 \%$ & $28 \%$ \\
\hline Equipe qualificada & $0 \%$ & $2 \%$ & $16 \%$ & $14 \%$ & $51 \%$ & $16 \%$ \\
\hline Gestor de projetos competente & $0 \%$ & $7 \%$ & $14 \%$ & $16 \%$ & $56 \%$ & $7 \%$ \\
\hline Objetivos claros e realistas & $0 \%$ & $5 \%$ & $7 \%$ & $12 \%$ & $53 \%$ & $23 \%$ \\
\hline Orçamento adequado & $14 \%$ & $21 \%$ & $14 \%$ & $21 \%$ & $23 \%$ & $7 \%$ \\
\hline Planejamento & $0 \%$ & $14 \%$ & $9 \%$ & $19 \%$ & $37 \%$ & $21 \%$ \\
Recursos suficientes & $0 \%$ & $5 \%$ & $7 \%$ & $30 \%$ & $40 \%$ & $19 \%$ \\
\hline Total geral & $\mathbf{1 \%}$ & $\mathbf{9 \%}$ & $\mathbf{1 1 \%}$ & $\mathbf{2 5 \%}$ & $\mathbf{3 6 \%}$ & $\mathbf{1 8 \%}$
\end{tabular}

Tabela 3 - Distribuição das respostas aos questionários 
$\mathrm{Na}$ tabela abaixo, apresentam-se os resultados separados apenas para os projetos avaliados como falha (17 projetos). A partir de sua análise, podemos observar:

- Apesar de o fator crítico de sucesso "Orçamento adequado" ter apenas $49 \%$ do total de respostas "Nenhum", "Muito baixo" e "Baixo", quando olhamos apenas para os projetos avaliados como falha, esse percentual sobe para $77 \%$. Isto pode indicar uma característica de que, pelo menos na empresa avaliada, há um bom planejamento de orçamento, dada a sua baixa importância no fracasso dos projetos;

- Como os fatores críticos de sucesso que mais influenciaram o fracasso dos projetos com $76 \%$ das respostas como "Muito alto", "Alto" e "Moderado", tem-se: "Recursos Suficientes" e "Complexidade do projeto".

\begin{tabular}{lcccccc} 
Fatores Críticos de Sucesso & Nenhum & Muito Baixo & Baixo & Moderado & Alto & Muito Alto \\
Apoio da alta gerência & $0 \%$ & $29 \%$ & $12 \%$ & $35 \%$ & $24 \%$ & $0 \%$ \\
Boa comunicação & $0 \%$ & $29 \%$ & $18 \%$ & $18 \%$ & $6 \%$ & $29 \%$ \\
Complexidade do projeto & $0 \%$ & $0 \%$ & $24 \%$ & $41 \%$ & $35 \%$ & $0 \%$ \\
Controle/ Monitoramento Efetivo & $0 \%$ & $6 \%$ & $29 \%$ & $41 \%$ & $24 \%$ & $0 \%$ \\
\hline Envolvimento do cliente & $0 \%$ & $18 \%$ & $24 \%$ & $41 \%$ & $0 \%$ & $18 \%$ \\
\hline Equipe qualificada & $0 \%$ & $0 \%$ & $41 \%$ & $18 \%$ & $41 \%$ & $0 \%$ \\
Gestor de projetos competente & $0 \%$ & $18 \%$ & $18 \%$ & $24 \%$ & $41 \%$ & $0 \%$ \\
\hline Objetivos claros e realistas & $0 \%$ & $12 \%$ & $18 \%$ & $6 \%$ & $47 \%$ & $18 \%$ \\
Orçamento adequado & $24 \%$ & $47 \%$ & $6 \%$ & $0 \%$ & $24 \%$ & $0 \%$ \\
\hline Planejamento & $0 \%$ & $35 \%$ & $12 \%$ & $6 \%$ & $35 \%$ & $12 \%$ \\
Recursos suficientes & $0 \%$ & $12 \%$ & $12 \%$ & $12 \%$ & $47 \%$ & $18 \%$ \\
\hline Total geral & $\mathbf{2 \%}$ & $\mathbf{1 9 \%}$ & $\mathbf{1 9 \%}$ & $\mathbf{2 2 \%}$ & $\mathbf{2 9 \%}$ & $\mathbf{9 \%}$
\end{tabular}

Tabela 4 - Distribuição das respostas aos questionários dos projetos identificados como falha 
$\mathrm{Na}$ tabela abaixo, apresentam-se os resultados separados apenas para os projetos avaliados como sucesso (26 projetos). A partir de sua análise, podemos observar:

- Apenas 9\% das respostas foram "Nenhum", "Muito baixo" e "Baixo", o que indica que todos os fatores críticos de sucesso possuem uma real importância na empresa em questão;

- Em $100 \%$ das respostas, "Objetivos claros e realistas" e "Boa comunicação" são avaliados "Muito alto", "Alto" e "Moderado". Isso reflete a grande importância que esses fatores possuem para o sucesso dos projetos;

\begin{tabular}{lcccccc} 
Fatores Críticos de Sucesso & Nenhum & Muito Baixo & Baixo & Moderado & Alto & Muito Alto \\
Apoio da alta gerência & $0 \%$ & $8 \%$ & $0 \%$ & $35 \%$ & $19 \%$ & $38 \%$ \\
Boa comunicação & $0 \%$ & $0 \%$ & $0 \%$ & $31 \%$ & $38 \%$ & $31 \%$ \\
Complexidade do projeto & $0 \%$ & $8 \%$ & $12 \%$ & $42 \%$ & $19 \%$ & $19 \%$ \\
\hline Controle/ Monitoramento Efetivo & $0 \%$ & $4 \%$ & $4 \%$ & $31 \%$ & $35 \%$ & $27 \%$ \\
\hline Envolvimento do cliente & $0 \%$ & $0 \%$ & $4 \%$ & $12 \%$ & $50 \%$ & $35 \%$ \\
\hline Equipe qualificada & $0 \%$ & $4 \%$ & $0 \%$ & $12 \%$ & $58 \%$ & $27 \%$ \\
Gestor de projetos competente & $0 \%$ & $0 \%$ & $12 \%$ & $12 \%$ & $65 \%$ & $12 \%$ \\
\hline Objetivos claros e realistas & $0 \%$ & $0 \%$ & $0 \%$ & $15 \%$ & $58 \%$ & $27 \%$ \\
\hline Orçamento adequado & $8 \%$ & $4 \%$ & $19 \%$ & $35 \%$ & $23 \%$ & $12 \%$ \\
\hline Planejamento & $0 \%$ & $0 \%$ & $8 \%$ & $27 \%$ & $38 \%$ & $27 \%$ \\
\hline Recursos suficientes & $0 \%$ & $0 \%$ & $4 \%$ & $42 \%$ & $35 \%$ & $19 \%$ \\
\hline Total geral & $\mathbf{1 \%}$ & $\mathbf{2 \%}$ & $\mathbf{6 \%}$ & $\mathbf{2 7 \%}$ & $\mathbf{4 0 \%}$ & $\mathbf{2 5 \%}$
\end{tabular}

Tabela 5 - Distribuição das respostas aos questionários dos projetos identificados como sucesso

A partir dos resultados já apresentados é interessante notar as diferenças no que tange ao sucesso e ao fracasso dos projetos na visão dos avaliados. Ao passo que há uma 
As percepções das pessoas foram ponderadas de acordo com a escala de impacto das respostas obtidas pelos questionários. Para a ponderação foram considerados os seguintes pesos:

- Nenhum: -3

- Muito Baixo: -2

- Baixo: -1

- Moderado: 1

- $\quad$ Alto: 2

- Muito Alto: -3

Os resultados ponderados de cada um dos fatores críticos de sucesso são mostrados na figura 11 a seguir. Podemos verificar, como esperado pelo observado nas tabelas 4 e 5, a ponderação levou a importância do fator "Orçamento adequado" ao menor patamar, enquanto "Objetivos Claros e Realistas" ao maior. 


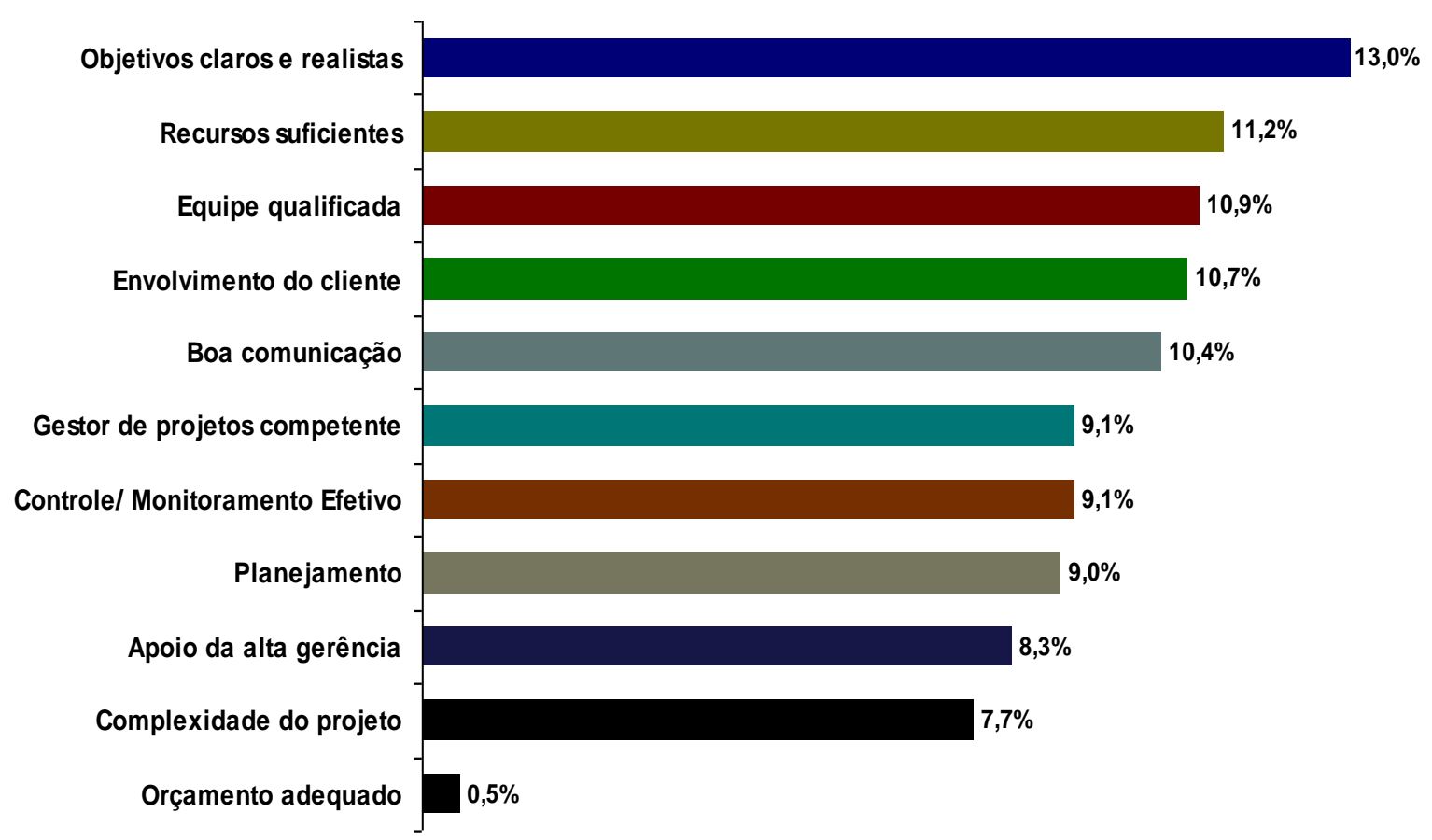

Figura 10 - Resultados ponderados da percepção da influência dos fatores críticos de sucesso em projetos.

Para analisar as diferenças entre os resultados obtidos para a área avaliada e aqueles obtidos pelo Standish Group, plotamos conjuntamente os dois resultados como mostrado na figura 11. 


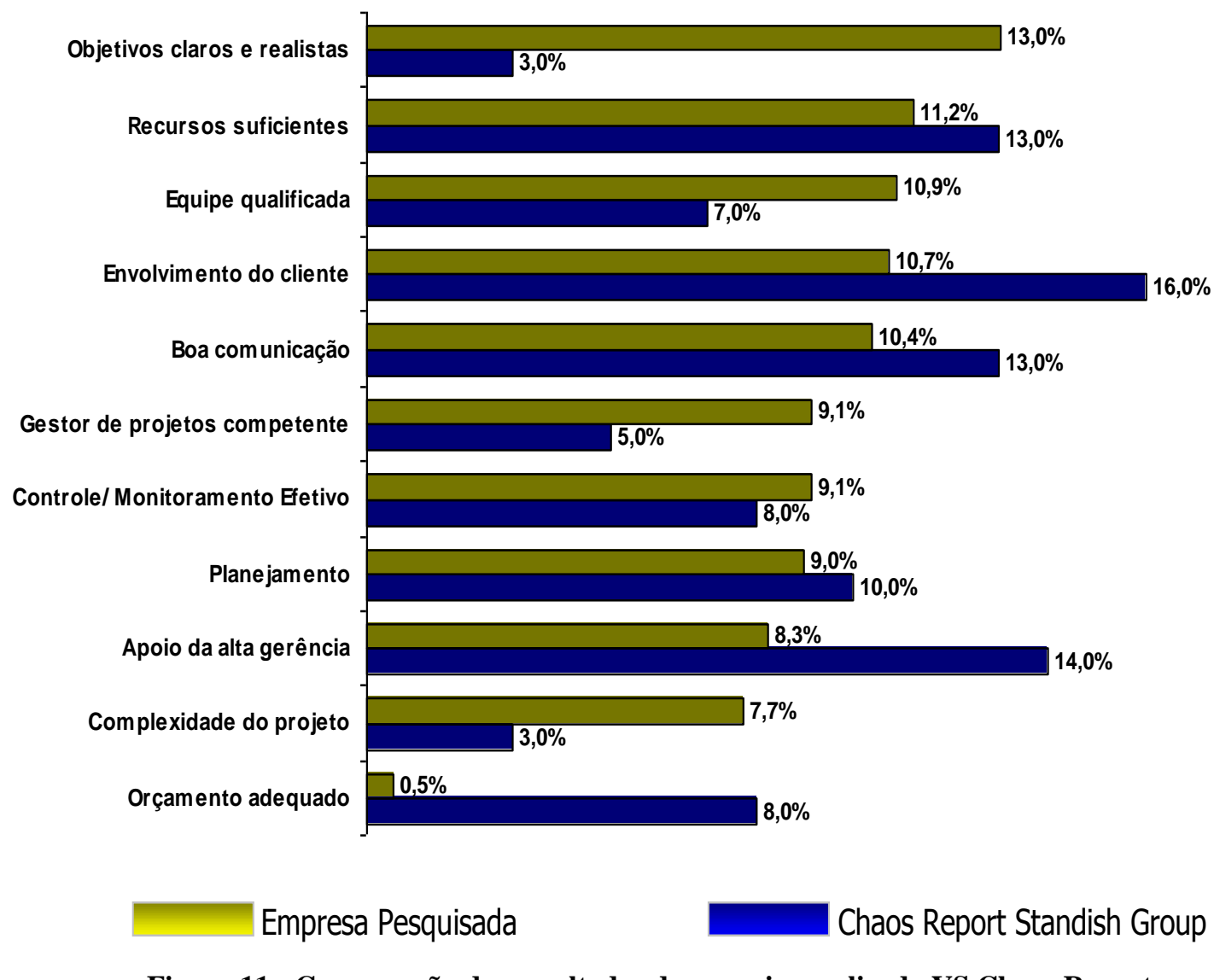

Figura 11 - Comparação dos resultados da pesquisa realizada VS Chaos Report.

Esse resultado mostra grandes diferenças entre as duas pesquisas. $\mathrm{O}$ que pode mostrar não apenas a realidade brasileira, mas também evidenciar a realidade de uma empresa do setor financeiro, ainda que não possamos generalizar os resultados para todo o setor.

Na figura 12, apresenta-se a ponderação dos resultados da percepção a respeito dos fatores críticos de sucesso separadamente entre os projetos avaliados como sucesso e aqueles avaliados como fracasso. Essa é a base para a utilização dos fatores críticos de sucesso como fatores de certeza. 

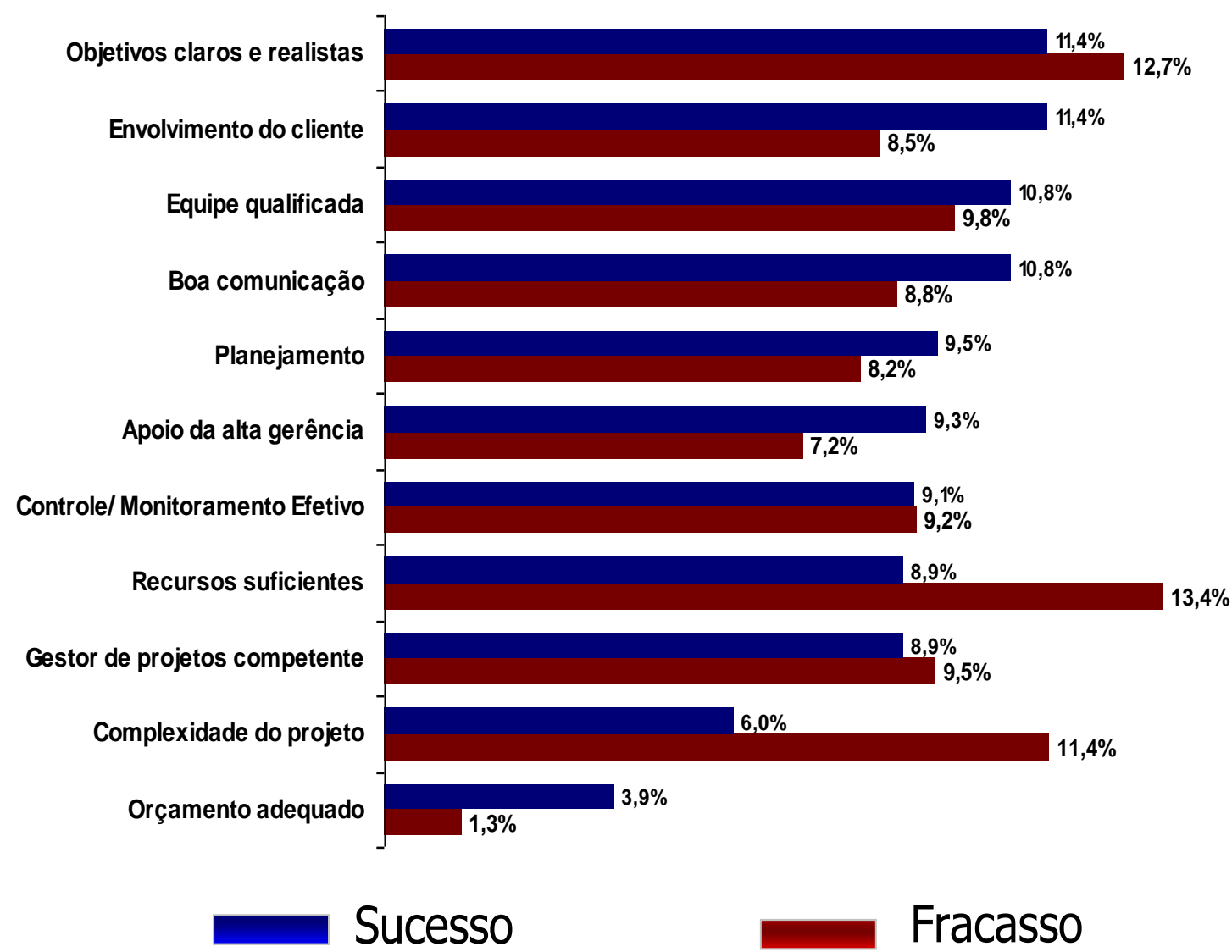

Figura 12 - Resultados da pesquisa separando as avaliações para os projetos que tiveram sucesso, daqueles que fracassaram.

A seguir, apresentam-se como os resultados são utilizados no sistema que dará o fator de certeza de sucesso de acordo com a avaliação do gestor a respeito dos fatores críticos de sucesso na situação atual do projeto.

O objetivo é que em qualquer momento do projeto o gestor possa fazer uma análise para identificar a presença ou ausência dos fatores críticos de sucesso e esse por sua vez, estimar o fator de certeza associado ao cenário apresentado pelo gestor. 
Os fatores críticos de sucesso se apresentam como as evidências, sendo que os fatores de certeza associados para a presença do fator crítico de sucesso são aqueles obtidos pela pesquisa e apresentados como sucesso na figura 12 e os fatores de certeza associados para a ausência do fator crítico de sucesso são aquele obtido pela pesquisa e apresentado como fracasso. A semente utilizada (CF0) para o fator de certeza de sucesso em projetos foi o percentual de sucesso dos projetos na área avaliada: 60,4\%. Esse resultado mostra mais uma vez a diferença entre a empresa avaliada e aquelas da pesquisa Chaos Report, dado que nessa pesquisa, o fator de sucesso em 2.008 foi de aproximadamente $32 \%$.

Abaixo, mostram-se alguns dos resultados obtidos para alguns cenários fictícios.

\begin{tabular}{|l|c|}
\hline \multicolumn{2}{|c|}{ FATOR CERTEZA NO SUCESSO DO PROJETO $=\mathbf{4 0 , 6 \%}$} \\
\hline \multicolumn{1}{|c|}{ MAIOR PONTO DE ATENÇÃO } & $\begin{array}{c}\text { Recursos suficientes } \\
\text { FATORES CRÍTICOS DE SUCESSO } \\
\text { (SIM/NÃO) }\end{array}$ \\
\hline Objetivos claros e realistas & SIM \\
\hline Equipe qualificada & SIM \\
\hline Gestor de projetos competente & NÃO \\
\hline Envolvimento do cliente & NÃO \\
\hline Planejamento & NÃO \\
\hline Recursos suficientes & NÃO \\
\hline Boa comunicação & NÃO \\
\hline Apoio da alta gerência & SIM \\
\hline Controle/ Monitoramento Efetivo & NÃO \\
\hline Complexidade do projeto & SIM \\
\hline Orçamento adequado & NÃO \\
\hline
\end{tabular}

Tabela 6 - Cenário fictício 1 com algumas respostas a respeito dos fatores críticos de sucesso

Nesse exemplo da utilização do sistema desenvolvido, colocam-se apenas três fatores críticos presentes: 
1. Objetivos claros e realistas

2. Equipe qualificada

3. Apoio da alta gerência

Como resultado, temos o fator de certeza no sucesso do projeto de $40,6 \%$, o que não permite afirmar que o sucesso terá sucesso, porém é um indicativo de que algo deve ser feito para aumentar as chances de que isso aconteça, nesse sentido, aponta qual fator crítico de sucesso, entre os não selecionados, tem a maior influência. Nesse caso, "Recursos Suficientes" deveria ser o primeiro ponto a ser atacado para o caminho do sucesso no projeto.

\begin{tabular}{|l|c|}
\hline \multicolumn{2}{|c|}{ FATOR CERTEZA NO SUCESSO DO PROJETO $=$ 73,9\% } \\
\hline \multicolumn{1}{|c|}{ MAIOR PONTO DE ATENÇÃO } & Controle/ Monitoramento Efetivo \\
\hline \multicolumn{1}{|c|}{ FATORES CRÍTICOS DE SUCESSO } & $\begin{array}{c}\text { No proto atual há? } \\
\text { (SIM/NÃO) }\end{array}$ \\
\hline \hline Objetivos claros e realistas & SIM \\
\hline Equipe qualificada & SIM \\
\hline Gestor de projetos competente & SIM \\
\hline Envolvimento do cliente & SIM \\
\hline Planejamento & NÃO \\
\hline Recursos suficientes & SIM \\
Boa comunicação & NÃO \\
\hline Apoio da alta gerência & SIM \\
\hline Controle/ Monitoramento Efetivo & NÃO \\
\hline Complexidade do projeto & NÃO \\
\hline Orçamento adequado & NÃO \\
\hline
\end{tabular}

Tabela 7 - Cenário fictício 2 com algumas respostas a respeito dos fatores críticos de sucesso 
Nesse exemplo da utilização do sistema desenvolvido, coloca-se, além dos fatores colocados no primeiro exemplo:

1. Gestor de projetos competente

2. Envolvimento do cliente

3. Recursos Suficientes

4. Complexidade do Projeto (nesse caso é considerado que não haver a complexidade, tem impacto positivo sobre o projeto)

Como era de se esperar, nesse caso o fator de certeza subiu de 40,6\% para $73,9 \%$ e o sistema aponta, entre os fatores que não foram selecionados, "Controle/Monitoramento Efetivo" como o maior ponto de atenção.

Na tabela 8, mostra-se o resultado do sistema ao se colocar as informações de um projeto real de desenvolvimento de sistema que resultou em sucesso. $\mathrm{O}$ resultado do sistema indicaria $79,4 \%$ de certeza no sucesso do projeto e como fator crítico de sucesso o "Controle / Monitoramente Efetivo" que realmente foi o aspecto que pecou um pouco no seu desenvolvimento. 
FATOR CERTEZA NO SUCESSO DO PROJETO = 79,4\%

\begin{tabular}{|l|c|}
\hline \multicolumn{2}{|c|}{ MAIOR PONTO DE ATENÇÃO $\Rightarrow$ Controle/ Monitoramento Efetivo } \\
\hline \multicolumn{1}{|c|}{ FATORES CRÍTICOS DE SUCESSO } & $\begin{array}{c}\text { No projeto atual há? } \\
\text { (SIM/NÃO) }\end{array}$ \\
\hline \hline Objetivos claros e realistas & sim \\
\hline Equipe qualificada & sim \\
\hline Gestor de projetos competente & sim \\
\hline Envolvimento do cliente & sim \\
\hline Planejamento & sim \\
\hline Recursos suficientes & sim \\
\hline Boa comunicação & não \\
\hline Apoio da alta gerência & sim \\
\hline Controle/ Monitoramento Efetivo & não \\
\hline Complexidade do projeto & não \\
\hline Orçamento adequado & sim \\
\hline
\end{tabular}

Tabela 8 - Cenário real de avaliação de projeto de sucesso de desenvolvimento de sistema

Na tabela 9, apresenta-se o resultado de um projeto de implantação de uma nova tecnologia e que não obteve êxito dentro dos requisitos de custo, prazo e escopo. O resultado do sistema apresentou um fator de certeza de 40,9\%. Como fator crítico de sucesso mais importante a ser atacado foi apresentado "Recursos suficientes", alinhado ao fator que mais contribuiu com o mau desempenho do projeto e demonstrando com esse resultado que poderíamos utilizar a ferramenta para auxiliar na gestão do projeto. 
FATOR CERTEZA NO SUCESSO DO PROJETO = 40,9\%

\begin{tabular}{|c|c|}
\hline MAIOR PONTO DE ATENÇÃO & Recursos suficientes \\
\hline FATORES CRÍTICOS DE SUCESSO & $\begin{array}{c}\text { No projeto atual há? } \\
\text { (SIM/NÃO) }\end{array}$ \\
\hline Objetivos claros e realistas & NÃO \\
\hline Equipe qualificada & SIM \\
\hline Gestor de projetos competente & NÃO \\
\hline Envolvimento do cliente & SIM \\
\hline Planejamento & NÃO \\
\hline Recursos suficientes & NÃO \\
\hline Boa comunicação & NÃO \\
\hline Apoio da alta gerência & SIM \\
\hline Controle/ Monitoramento Efetivo & NÃO \\
\hline Complexidade do projeto & SIM \\
\hline Orçamento adequado & SIM \\
\hline
\end{tabular}

Tabela 9 - Cenário real de avaliação de projeto de fracasso de implantação de uma nova tecnologia 


\section{Considerações finais}

Os resultados apontam inicialmente para uma divergência entre a realidade da empresa em questão e aquelas pesquisadas pelo Standish Group e compiladas na pesquisa denominada Chaos Report. O que pode refletir não apenas a realidade brasileira, mas a realidade da empresa pesquisada com projetos de baixo orçamento e que nesse aspecto estariam em conformidade com a pesquisa supracitada, lembrando que conforme já citado, o estudo do Standish Group aponta que $61 \%$ dos projetos com orçamento inferior a US\$700mil obtém sucesso.

Para dar continuidade ao trabalho apresentado nesta pesquisa apontam-se os seguintes pontos a serem seguidos:

- Aumentar a pesquisa e o seu escopo buscando aumentar as variáveis a serem estudadas e, assim, possibilitar o desenvolvimento de novas formas de orientação ao gestor de projetos;

- Avaliação da interdependência entre os fatores críticos de sucesso;

- A utilização de outra técnica conjuntamente com os fatores de certeza para agregar valor às informações;

- Uma análise estatística para verificar a existência de correlação entre as respostas do questionário e posterior ajuste na base de dados pode tornar os resultados mais factíveis;

- O agrupamento dos projetos dos projetos pode ser uma alternativa para a análise a ser realizada, dado que projetos semelhantes poderiam apresentar pesos diferenciados para os fatores críticos de sucesso; 
- Desenvolver o sistema de forma a habilitá-lo a simular quais seriam as entradas complementares que possibilitariam o aumento do fator de certeza para um nível acima de $50 \%$ e não apenas o maior ponto de atenção;

- Desenvolvimento de um modelo para a simulação das diversas fases do projeto e da influência dos fatores críticos de sucesso em cada uma dessas fases, assim, seria possível orientar de maneira mais efetiva o gestor de projetos no caminho a ser tomado dado o status e a fase do projeto.

A lista de fatores citados na literatura é bastante extensa, fato que evidencia ainda mais ser improvável que eles sejam aplicáveis como críticos em qualquer tipo de projeto, além disso, ainda que o ataque e direcionamento das ações no caminho dos fatores críticos de sucesso, as variáveis inerentes a um sistema tão complexo como um projeto pode nem sempre resultar no sucesso do projeto. É interessante, portanto, avaliar os fatores que se aplicam a projetos de um mesmo tipo, executados em organizações similares.

O fato de tratarmos apenas uma empresa e uma amostra de um de seus vários departamentos não nos permite generalizar os resultados observados.

Ainda que incipiente, essa forma de abordagem mostra que o acompanhamento do projeto e de seus fatores críticos de sucesso, em qualquer uma de suas fases, pode conduzir à adoção de medidas, não apenas pelo gestor de projetos, mas também por toda a equipe envolvida na sua definição, planejamento e execução. 


\section{Referências}

CARVALHO, M. M.; RABECHINI JR, R. Construindo Competências para Gerenciar Projetos. Atlas: São Paulo, 2005.

CLELAND, David .I; BURSIC, King. M.; PUERZER, R.; VLASAK, Yaroslav. Project Management Casebook, Upper Darby: Project Management Institute, 1997

DANIEL, D.R. "Management information crisis", Harvard Business Review, No.September/October, pp.111-21, 1961.

DVIR, D.; SADEH, A.; MALACH-PINES, A. Projects and Project Managers: The Relationship between Project Managers' Personality, Project Types and Project Success. Project Management Journal, Vol. 37, No. 5, pp. 36-48, 2006.

FORTUNE, J.; WHITE, D. Framing of project critical success factors by a systems model. International Journal of Project Management, Vol. 24, pp. 53-65, 2006.

GONZALEZ, A.J.; DANKEL, D.D. The Engineering of Knowledge-Based Systems Theory and Practice. Prentice Hall, Englewood Cliffs, USA, 1993

HARMON, P. \& KING, D.; Expert Systems. John Wiley\&Sons, Inc., 1985 
HAYES, R.; PISANO, G.; UPTON, D.; WHEELWRIGHT, S. Operations, Strategy, and Technology: Pursuing the Competitive Edge. Hoboken: John Wiley \& Sons, 2005.

HYVÄRI, I. Success of Project in Different Organizational Conditions. Project Management Journal, Vol. 37, No. 4, pp. 31-41, 2006.

JUDGEV, K.; MÜLLER, R. A Retrospective Look at Our Evolving Understanding of Project Success. Project Management Journal, Vol. 36, No. 4, pp. 19-31, 2005.

KERZNER, H. Strategic planning for project management using a project management maturity model. New York: John Wiley \& Sons, 1999.

KING, W.R. The Role of Projects in the Implementation of Business Strategy in: CLELAND, D.I. \& KING, W.R. Project Management Handbook. Van Nostrand Reinhold, New York, 1993.

KNIGHT, G. Entrepreneurship and Marketing Strategy: The SME under Globalization. Journal of International Marketing, v. 8, n. 2, p. 12-32, 2000.

MAXIMIANO, A. C. A. (1997). Administração de Projetos. Atlas: São Paulo. 
McADAM, R.; DONAGHY, J. Business process re-engineering in the public sector - A study of staff perceptions and critical success factors. Business Process Management Journal, Vol. 5 No. 1, p. 33-49, 1999.

MEREDITH, Jack R. \& Mantel JR., Samuel J. Project Management: A Managerial Approach. New York: John Wiley and Sons, 1995

PIQUEIRA, J. R. C, Revista Eletrônica Informação e Cognição, v.2, n.1, p.28-36, 2000.

PMI, Project Management Institute. A Guide to the Project Management Body of Knowledge (PMBoK), 3.ed. Project Management Institute Inc.: Newtown Square, 2004.

PRABHAKAR, G. P. An Empirical Study Reflecting the Importance of Transformational Leadership on Project Success across Twenty-eight Nations. Project Management Journal, Vol. 36, No. 4; pp. 53-60, 2005.

RABECHINI, ROQUE JR, Um modelo estruturado de competências e maturidade em gerenciamento de projetos Prod. vol.15 no. 1 São Paulo Jan./Abr. 2005

SOMMERVILLE, IAN, Engenharia de Software, Pearson Addison Wesley, São Paulo, 2003 
STANDISH GROUP INTERNATIONAL, Chaos report. Disponível em:

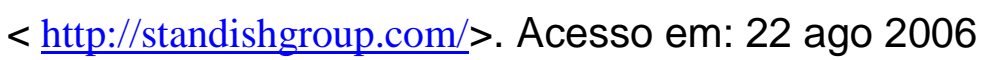

TURNER, J. R.; MÜLLER, R. The Project Manager's Leadership Style as a Success Factor on Projects: A Literature Review. Project Management Journal, Vol. 36, No. 2, pp. 49-61, 2005.

VOSS, C.; TSIKRIKTSIS, N \& FROHLICH, M. Case research in operations management. International Journal of Operations \& Production Management. Vol. 22 No. 2, 2002.

WIKIPEDIA, Mycin disponível em:

<http://en.wikipedia.org/wiki/Mycin>. Acesso em: 25 mai. 2008 


\section{Apêndice A - Formalismo dos Fatores de Certeza (CF)}

Nesse trabalho, inicialmente utilizamos a teoria de Fatores de Certeza para estudar a percepção dos envolvidos em projetos com relação à influência dos fatores críticos de sucesso para o sucesso ou fracasso dos mesmos. Baseado no modelo, um especialista humano deve basear sua incerteza com relação a uma hipótese $\mathrm{H}$ de uma regra:

"Se E (Evidência) então H (Hipótese)",

como um fator de certeza $\mathrm{CF}[\mathrm{H}, \mathrm{E}]$.

O fator de certeza varia de 1 , certeza absoluta, a -1 que indica a descrença total na hipótese dada a evidência. Fatores de certeza não são medidas de probabilidade, são medidas informais de confiança ou certeza com relação a uma evidência.

Um fator de certeza positivo é associado à hipótese $H$ dada a evidência $E$ se existir algum grau de confirmação em $\mathrm{H}$, dada a observação $\mathrm{E}$. O fator de certeza $\mathrm{CF}[\mathrm{H}, \mathrm{E}]=1$ indica que a ocorrência de $\mathrm{E}$ prova completamente a hipótese $\mathrm{H}$.

O fator de certeza negativo é adotado pelo especialista se a observação da evidência $E$ desconfirma a hipótese $\mathrm{H}$. Um fator de certeza 0 (zero) é atribuído se a observação de $E$ não influencia a confiança na hipótese $\mathrm{H}$.

A definição do fator de certeza de uma hipótese dada a evidência $E$ envolve o cálculo de duas funções intermediárias: 
- $\mathrm{MB}[\mathrm{H}, \mathrm{E}]$ : mede o grau de aumento da crença na hipótese $H$, se $E$ for observada.

- $\mathrm{MD}[\mathrm{H}, \mathrm{E}]$ : mede o grau de aumento da descrença na hipótese $\mathrm{H}$, se $\mathrm{E}$ for observada.

Ambas as medidas, MB e MD, são definidas em função de:

- $\mathrm{p}(\mathrm{H})$ : probabilidade a priori de $\mathrm{H}$

- $\mathrm{p}(\mathrm{H} \mid \mathrm{E})$ : probabilidade a posteriori de $\mathrm{H}$ ou probabilidade condicional, dada a evidência $E$

A medida do aumento de crença MB é uma função que associa dois argumentos: a hipótese $\mathrm{H}$ e uma evidência $\mathrm{E}$ a um valor no intervalo $[0,1]$. A MB de uma hipótese H dada a evidência $E$ pode ser pensada como a diminuição proporcional da descrença em $\mathrm{H}$ dada $\mathrm{E}$ e é equacionada em função de probabilidades como:

$$
M B(H, E)=\left\{\begin{array}{cc}
1 & \text { se } \mathrm{p}(\mathrm{H})=1 \\
\frac{\operatorname{Max}[p(H, E), p(H)]-p(H)}{1-p(H)} & \text { Caso contrário }
\end{array}\right.
$$

De maneira análoga, a medida do aumento de descrença MD é a diminuição proporcional da crença em $\mathrm{H}$, como resultado da evidência $\mathrm{E}$. A medida do aumento de descrença também é uma função que associa dois argumentos: a hipótese $\mathrm{He}$ 
uma evidência $E$ a um valor no intervalo $[0,1]$ e é equacionada em função de probabilidades como:

$$
M D(H, E)=\left\{\begin{array}{cl}
1 & \text { se } \mathrm{p}(\mathrm{H})=0 \\
\frac{\operatorname{Min}[p(H, E), p(H)]-p(H)}{-p(H)} & \text { Caso contrário }
\end{array}\right.
$$

O fator de certeza, CF, o qual é composto de $M B$ e MD e variando de -1 (completa negação) a 1 (completa confirmação). Este valor é calculado como:

$$
C F(H, E)=\frac{M B-M D}{1-\min (M B, M D)}
$$

Propagação de Fatores de Certeza (CF)

De acordo com a aquisição de conhecimento a respeito de determinado problema, várias regras são capazes de conduzir à mesma hipótese ou conclusão. Por essa razão, deve-se ter um mecanismo para combinar os fatores de certeza associado a cada uma das regras com quaisquer outras para resultar em um único resultado para a hipótese. Abaixo, encontram-se as regras para a determinação do CF resultante da combinação de dois outros. 


$$
C F_{R}\left(C F_{0}, C F_{1}\right)=\left\{\begin{array}{cl}
C F_{0}+C F_{1} \times\left(1-C F_{0}\right) & \text { Se CF0 }>0 \text { e CF1 }>0 \\
-C F_{R}\left(-C F_{0},-C F_{1}\right)=C F_{0}+C F_{1} \times\left(1+C F_{0}\right) & \text { Se CF0 }<0 \text { e CF1 }<0 \\
\frac{C F_{0}+C F_{1} \times\left(1-C F_{0}\right)}{1-\min \left(\left|C F_{0}\right|,\left|C F_{1}\right|\right)} & \text { Se CF0 }>0 \text { e CF1 }<0 \text { ou } \\
& \text { Se CF0 }<0 \text { e } C F 1>0 \text { p }(\mathrm{H})=0
\end{array}\right.
$$

Evidências incertas

A utilização das equações colocadas no item anterior é oriunda da premissa de que se tem absoluta confiança nas premissas ou evidências utilizadas para derivar estes valores. Para o caso em que isso não acontece, temos:

1. $\mathrm{O} \mathrm{CF}_{\mathrm{R}}$ (Fator de Certeza Resultante) seria o produto do CF da hipótese e do CF da evidência.

2. Se a regra consiste de uma conjunção de premissas, então o $\mathrm{CF}_{\mathrm{R}}$ é o produto do CF da hipótese e do mínimo CF associado às evidências.

3. Se a regra consiste de uma disjunção de premissas, então o $\mathrm{CF}_{\mathrm{R}}$ é o produto do CF da hipótese e do máximo CF associado às evidências. 


\section{APÊNDICE B - Resultados da pesquisa de campo: projetos avaliados como sucesso.}

\begin{tabular}{|c|c|c|c|c|c|c|c|}
\hline Projeto & Fator crítico de sucesso & Nenhum & $\begin{array}{c}\text { Muito } \\
\text { Baixo }\end{array}$ & Baixo & Moderado & Alto & $\begin{array}{c}\text { Muito } \\
\text { Alto }\end{array}$ \\
\hline 1 & Apoio da alta gerência & & & & & & $\mathrm{x}$ \\
\hline 1 & Boa comunicação & & & & $\mathrm{x}$ & & \\
\hline 1 & Complexidade do projeto & & & & $\mathrm{x}$ & & \\
\hline 1 & $\begin{array}{l}\text { Controle/ Monitoramento } \\
\text { Efetivo }\end{array}$ & & & & & $\mathrm{x}$ & \\
\hline 1 & Envolvimento do cliente & & & & & $\mathrm{x}$ & \\
\hline 1 & Equipe qualificada & & & & $\mathrm{x}$ & & \\
\hline 1 & Gestor de projetos competente & & & & $\mathrm{x}$ & & \\
\hline 1 & Objetivos claros e realistas & & & & & $\mathrm{x}$ & \\
\hline 1 & Orçamento adequado & & & $\mathrm{x}$ & & & \\
\hline 1 & Planejamento & & & & & $\mathrm{x}$ & \\
\hline 1 & Recursos suficientes & & & & & $\mathrm{x}$ & \\
\hline 2 & Apoio da alta gerência & & & & & $\mathrm{x}$ & \\
\hline 2 & Boa comunicação & & & & $\mathrm{x}$ & & \\
\hline 2 & Complexidade do projeto & & & & $\mathrm{x}$ & & \\
\hline 2 & $\begin{array}{l}\text { Controle/ Monitoramento } \\
\text { Efetivo }\end{array}$ & & & & $x$ & & \\
\hline 2 & Envolvimento do cliente & & & & & $\mathrm{x}$ & \\
\hline 2 & Equipe qualificada & & & & & & $\mathrm{x}$ \\
\hline 2 & Gestor de projetos competente & & & $x$ & & & \\
\hline 2 & Objetivos claros e realistas & & & & & $\mathrm{x}$ & \\
\hline 2 & Orçamento adequado & & & & & $x$ & \\
\hline 2 & Planejamento & & & & & & $\mathrm{x}$ \\
\hline 2 & Recursos suficientes & & & & $\mathrm{x}$ & & \\
\hline 3 & Apoio da alta gerência & & & & & & $\mathrm{x}$ \\
\hline 3 & Boa comunicação & & & & & $x$ & \\
\hline 3 & Complexidade do projeto & & & & $\mathrm{x}$ & & \\
\hline 3 & $\begin{array}{l}\text { Controle/ Monitoramento } \\
\text { Efetivo }\end{array}$ & & & $\mathrm{x}$ & & & \\
\hline 3 & Envolvimento do cliente & & & & & & $\mathrm{x}$ \\
\hline 3 & Equipe qualificada & & & & & $x$ & \\
\hline 3 & Gestor de projetos competente & & & $\mathrm{x}$ & & & \\
\hline 3 & Objetivos claros e realistas & & & & & $\mathrm{x}$ & \\
\hline 3 & Orçamento adequado & & & $x$ & & & \\
\hline 3 & Planejamento & & & & & $\mathrm{x}$ & \\
\hline 3 & Recursos suficientes & & & & $\mathrm{x}$ & & \\
\hline
\end{tabular}

Tabela 10 - Resultados da pesquisa de campo - projetos avaliados como sucesso - projetos 1 ao 3 


\begin{tabular}{|c|c|c|c|c|c|c|c|}
\hline Projeto & Fator crítico de sucesso & Nenhum & $\begin{array}{l}\text { Muito } \\
\text { Baixo }\end{array}$ & Baixo & Moderado & Alto & $\begin{array}{l}\text { Muito } \\
\text { Alto }\end{array}$ \\
\hline 4 & Apoio da alta gerência & & & & & & $\mathrm{x}$ \\
\hline 4 & Boa comunicação & & & & & & $x$ \\
\hline 4 & Complexidade do projeto & & & & & & $\mathrm{x}$ \\
\hline 4 & $\begin{array}{l}\text { Controle/ Monitoramento } \\
\text { Efetivo }\end{array}$ & & & & & $x$ & \\
\hline 4 & Envolvimento do cliente & & & & & $x$ & \\
\hline 4 & Equipe qualificada & & & & $x$ & & \\
\hline 4 & Gestor de projetos competente & & & & & $x$ & \\
\hline 4 & Objetivos claros e realistas & & & & & $x$ & \\
\hline 4 & Orçamento adequado & & & & & $x$ & \\
\hline 4 & Planejamento & & & & & $x$ & \\
\hline 4 & Recursos suficientes & & & & & $x$ & \\
\hline 5 & Apoio da alta gerência & & & & & & $\mathrm{x}$ \\
\hline 5 & Boa comunicação & & & & & $x$ & \\
\hline 5 & Complexidade do projeto & & & & & & $\mathrm{x}$ \\
\hline 5 & $\begin{array}{l}\text { Controle/ Monitoramento } \\
\text { Efetivo }\end{array}$ & & & & & & $x$ \\
\hline 5 & Envolvimento do cliente & & & & & & $\mathrm{x}$ \\
\hline 5 & Equipe qualificada & & & & & & $\mathrm{x}$ \\
\hline 5 & Gestor de projetos competente & & & & & $x$ & \\
\hline 5 & Objetivos claros e realistas & & & & & $x$ & \\
\hline 5 & Orçamento adequado & & & & & $x$ & \\
\hline 5 & Planejamento & & & & $\mathrm{x}$ & & \\
\hline 5 & Recursos suficientes & & & & & $x$ & \\
\hline 6 & Apoio da alta gerência & & & & & $x$ & \\
\hline 6 & Boa comunicação & & & & & & $\mathrm{x}$ \\
\hline 6 & Complexidade do projeto & & $x$ & & & & \\
\hline 6 & $\begin{array}{l}\text { Controle/ Monitoramento } \\
\text { Efetivo }\end{array}$ & & & & & $x$ & \\
\hline 6 & Envolvimento do cliente & & & & & $x$ & \\
\hline 6 & Equipe qualificada & & & & & $x$ & \\
\hline 6 & Gestor de projetos competente & & & & & $x$ & \\
\hline 6 & Objetivos claros e realistas & & & & & & $\mathrm{x}$ \\
\hline 6 & Orçamento adequado & & & $\mathrm{x}$ & & & \\
\hline 6 & Planejamento & & & & & & $\mathrm{x}$ \\
\hline 6 & Recursos suficientes & & & & $\mathrm{x}$ & & \\
\hline
\end{tabular}

Tabela 11 - Resultados da pesquisa de campo - projetos avaliados como sucesso - projetos 4 ao 6 


\begin{tabular}{|c|c|c|c|c|c|c|c|}
\hline Projeto & Fator crítico de sucesso & Nenhum & $\begin{array}{l}\text { Muito } \\
\text { Baixo }\end{array}$ & Baixo & Moderado & Alto & $\begin{array}{l}\text { Muito } \\
\text { Alto }\end{array}$ \\
\hline 7 & Apoio da alta gerência & & & & $x$ & & \\
\hline 7 & Boa comunicação & & & & & $x$ & \\
\hline 7 & Complexidade do projeto & & & $x$ & & & \\
\hline 7 & $\begin{array}{l}\text { Controle/ Monitoramento } \\
\text { Efetivo }\end{array}$ & & & & $x$ & & \\
\hline 7 & Envolvimento do cliente & & & & & $x$ & \\
\hline 7 & Equipe qualificada & & & & & $x$ & \\
\hline 7 & Gestor de projetos competente & & & & & & $x$ \\
\hline 7 & Objetivos claros e realistas & & & & $x$ & & \\
\hline 7 & Orçamento adequado & & & $x$ & & & \\
\hline 7 & Planejamento & & & & & $x$ & \\
\hline 7 & Recursos suficientes & & & & $x$ & & \\
\hline 8 & Apoio da alta gerência & & & & & $x$ & \\
\hline 8 & Boa comunicação & & & & & & $x$ \\
\hline 8 & Complexidade do projeto & & & & & & $x$ \\
\hline 8 & $\begin{array}{l}\text { Controle/ Monitoramento } \\
\text { Efetivo }\end{array}$ & & & & & & $x$ \\
\hline 8 & Envolvimento do cliente & & & & & & $x$ \\
\hline 8 & Equipe qualificada & & & & & $x$ & \\
\hline 8 & Gestor de projetos competente & & & $x$ & & & \\
\hline 8 & Objetivos claros e realistas & & & & & $x$ & \\
\hline 8 & Orçamento adequado & & & & $x$ & & \\
\hline 8 & Planejamento & & & & $x$ & & \\
\hline 8 & Recursos suficientes & & & $x$ & & & \\
\hline 9 & Apoio da alta gerência & & & & & & $x$ \\
\hline 9 & Boa comunicação & & & & $x$ & & \\
\hline 9 & Complexidade do projeto & & & $x$ & & & \\
\hline 9 & $\begin{array}{l}\text { Controle/ Monitoramento } \\
\text { Efetivo }\end{array}$ & & & & $x$ & & \\
\hline 9 & Envolvimento do cliente & & & & & & $x$ \\
\hline 9 & Equipe qualificada & & & & & & $x$ \\
\hline 9 & Gestor de projetos competente & & & & & $x$ & \\
\hline 9 & Objetivos claros e realistas & & & & & $x$ & \\
\hline 9 & Orçamento adequado & & & & $x$ & & \\
\hline 9 & Planejamento & & & & & $x$ & \\
\hline 9 & Recursos suficientes & & & & $x$ & & \\
\hline
\end{tabular}

Tabela 12 - Resultados da pesquisa de campo - projetos avaliados como sucesso - projetos 7 ao 9 


\begin{tabular}{|c|c|c|c|c|c|c|c|}
\hline Projeto & Fator crítico de sucesso & Nenhum & $\begin{array}{l}\text { Muito } \\
\text { Baixo }\end{array}$ & Baixo & Moderado & Alto & $\begin{array}{l}\text { Muito } \\
\text { Alto }\end{array}$ \\
\hline 10 & Apoio da alta gerência & & & & & & $x$ \\
\hline 10 & Boa comunicação & & & & & $x$ & \\
\hline 10 & Complexidade do projeto & & & & & $x$ & \\
\hline 10 & $\begin{array}{l}\text { Controle/ Monitoramento } \\
\text { Efetivo }\end{array}$ & & & & & $x$ & \\
\hline 10 & Envolvimento do cliente & & & & & $x$ & \\
\hline 10 & Equipe qualificada & & & & & $x$ & \\
\hline 10 & Gestor de projetos competente & & & & & $x$ & \\
\hline 10 & Objetivos claros e realistas & & & & & $x$ & \\
\hline 10 & Orçamento adequado & & & & $x$ & & \\
\hline 10 & Planejamento & & & & & $x$ & \\
\hline 10 & Recursos suficientes & & & & $x$ & & \\
\hline 11 & Apoio da alta gerência & & & & $x$ & & \\
\hline 11 & Boa comunicação & & & & $x$ & & \\
\hline 11 & Complexidade do projeto & & & & $x$ & & \\
\hline 11 & $\begin{array}{l}\text { Controle/ Monitoramento } \\
\text { Efetivo }\end{array}$ & & & & $x$ & & \\
\hline 11 & Envolvimento do cliente & & & & $\mathrm{x}$ & & \\
\hline 11 & Equipe qualificada & & & & & $x$ & \\
\hline 11 & Gestor de projetos competente & & & & & $x$ & \\
\hline 11 & Objetivos claros e realistas & & & & & $x$ & \\
\hline 11 & Orçamento adequado & & & & $x$ & & \\
\hline 11 & Planejamento & & & & $x$ & & \\
\hline 11 & Recursos suficientes & & & & $x$ & & \\
\hline 12 & Apoio da alta gerência & & & & $\mathrm{x}$ & & \\
\hline 12 & Boa comunicação & & & & & $x$ & \\
\hline 12 & Complexidade do projeto & & & & $x$ & & \\
\hline 12 & $\begin{array}{l}\text { Controle/ Monitoramento } \\
\text { Efetivo }\end{array}$ & & & & $x$ & & \\
\hline 12 & Envolvimento do cliente & & & & $x$ & & \\
\hline 12 & Equipe qualificada & & & & & $x$ & \\
\hline 12 & Gestor de projetos competente & & & & & $x$ & \\
\hline 12 & Objetivos claros e realistas & & & & & $x$ & \\
\hline 12 & Orçamento adequado & & & & $x$ & & \\
\hline 12 & Planejamento & & & & & $x$ & \\
\hline 12 & Recursos suficientes & & & & $x$ & & \\
\hline
\end{tabular}

Tabela 13 - Resultados da pesquisa de campo - projetos avaliados como sucesso - projetos 10 ao 12 


\begin{tabular}{|c|c|c|c|c|c|c|c|}
\hline Projeto & Fator crítico de sucesso & Nenhum & $\begin{array}{l}\text { Muito } \\
\text { Baixo }\end{array}$ & Baixo & Moderado & Alto & $\begin{array}{l}\text { Muito } \\
\text { Alto }\end{array}$ \\
\hline 13 & Apoio da alta gerência & & & & $x$ & & \\
\hline 13 & Boa comunicação & & & & $x$ & & \\
\hline 13 & Complexidade do projeto & & & & & & $x$ \\
\hline 13 & $\begin{array}{l}\text { Controle/ Monitoramento } \\
\text { Efetivo }\end{array}$ & & & & $\mathrm{x}$ & & \\
\hline 13 & Envolvimento do cliente & & & & & $x$ & \\
\hline 13 & Equipe qualificada & & & & & $x$ & \\
\hline 13 & Gestor de projetos competente & & & & $x$ & & \\
\hline 13 & Objetivos claros e realistas & & & & $x$ & & \\
\hline 13 & Orçamento adequado & & & & $x$ & & \\
\hline 13 & Planejamento & & & & $\mathrm{x}$ & & \\
\hline 13 & Recursos suficientes & & & & $x$ & & \\
\hline 14 & Apoio da alta gerência & & & & & $x$ & \\
\hline 14 & Boa comunicação & & & & $x$ & & \\
\hline 14 & Complexidade do projeto & & & & & $x$ & \\
\hline 14 & $\begin{array}{l}\text { Controle/ Monitoramento } \\
\text { Efetivo }\end{array}$ & & & & & $\mathrm{x}$ & \\
\hline 14 & Envolvimento do cliente & & & & $x$ & & \\
\hline 14 & Equipe qualificada & & & & & $x$ & \\
\hline 14 & Gestor de projetos competente & & & & & $x$ & \\
\hline 14 & Objetivos claros e realistas & & & & & $x$ & \\
\hline 14 & Orçamento adequado & & & & $x$ & & \\
\hline 14 & Planejamento & & & & $x$ & & \\
\hline 14 & Recursos suficientes & & & & & $x$ & \\
\hline 15 & Apoio da alta gerência & & & & $x$ & & \\
\hline 15 & Boa comunicação & & & & & $\mathrm{x}$ & \\
\hline 15 & Complexidade do projeto & & & $x$ & & & \\
\hline 15 & $\begin{array}{l}\text { Controle/ Monitoramento } \\
\text { Efetivo }\end{array}$ & & & & & & $\mathrm{x}$ \\
\hline 15 & Envolvimento do cliente & & & & & $x$ & \\
\hline 15 & Equipe qualificada & & & & $x$ & & \\
\hline 15 & Gestor de projetos competente & & & & & $x$ & \\
\hline 15 & Objetivos claros e realistas & & & & & $x$ & \\
\hline 15 & Orçamento adequado & & & $\mathrm{x}$ & & & \\
\hline 15 & Planejamento & & & & & $x$ & \\
\hline 15 & Recursos suficientes & & & & $x$ & & \\
\hline
\end{tabular}

Tabela 14 - Resultados da pesquisa de campo - projetos avaliados como sucesso - projetos 13 ao 15 


\begin{tabular}{|c|c|c|c|c|c|c|c|}
\hline Projeto & Fator crítico de sucesso & Nenhum & $\begin{array}{l}\text { Muito } \\
\text { Baixo }\end{array}$ & Baixo & Moderado & Alto & $\begin{array}{l}\text { Muito } \\
\text { Alto }\end{array}$ \\
\hline 16 & Apoio da alta gerência & & $x$ & & & & \\
\hline 16 & Boa comunicação & & & & & $x$ & \\
\hline 16 & Complexidade do projeto & & & & $x$ & & \\
\hline 16 & $\begin{array}{l}\text { Controle/ Monitoramento } \\
\text { Efetivo }\end{array}$ & & $\mathrm{x}$ & & & & \\
\hline 16 & Envolvimento do cliente & & & & & & $\mathrm{x}$ \\
\hline 16 & Equipe qualificada & & & & & $x$ & \\
\hline 16 & Gestor de projetos competente & & & & & $x$ & \\
\hline 16 & Objetivos claros e realistas & & & & $x$ & & \\
\hline 16 & Orçamento adequado & & & & $x$ & & \\
\hline 16 & Planejamento & & & & $x$ & & \\
\hline 16 & Recursos suficientes & & & & & $x$ & \\
\hline 17 & Apoio da alta gerência & & & & & $x$ & \\
\hline 17 & Boa comunicação & & & & & $x$ & \\
\hline 17 & Complexidade do projeto & & & & & & $\mathrm{x}$ \\
\hline 17 & $\begin{array}{l}\text { Controle/ Monitoramento } \\
\text { Efetivo }\end{array}$ & & & & & & $\mathrm{x}$ \\
\hline 17 & Envolvimento do cliente & & & & & & $\mathrm{x}$ \\
\hline 17 & Equipe qualificada & & & & & $x$ & \\
\hline 17 & Gestor de projetos competente & & & & & $x$ & \\
\hline 17 & Objetivos claros e realistas & & & & $x$ & & \\
\hline 17 & Orçamento adequado & & $x$ & & & & \\
\hline 17 & Planejamento & & & & $x$ & & \\
\hline 17 & Recursos suficientes & & & & & $x$ & \\
\hline 18 & Apoio da alta gerência & & & & $x$ & & \\
\hline 18 & Boa comunicação & & & & & $\mathrm{x}$ & \\
\hline 18 & Complexidade do projeto & & & & $x$ & & \\
\hline 18 & $\begin{array}{l}\text { Controle/ Monitoramento } \\
\text { Efetivo }\end{array}$ & & & & $x$ & & \\
\hline 18 & Envolvimento do cliente & & & & & $x$ & \\
\hline 18 & Equipe qualificada & & & & & & $x$ \\
\hline 18 & Gestor de projetos competente & & & & $x$ & & \\
\hline 18 & Objetivos claros e realistas & & & & & & $\mathrm{x}$ \\
\hline 18 & Orçamento adequado & & & & $x$ & & \\
\hline 18 & Planejamento & & & & & & $\mathrm{x}$ \\
\hline 18 & Recursos suficientes & & & & & & $x$ \\
\hline
\end{tabular}

Tabela 15 - Resultados da pesquisa de campo - projetos avaliados como sucesso - projetos 16 ao 18 


\begin{tabular}{|c|c|c|c|c|c|c|c|}
\hline Projeto & Fator crítico de sucesso & Nenhum & $\begin{array}{l}\text { Muito } \\
\text { Baixo }\end{array}$ & Baixo & Moderado & Alto & $\begin{array}{c}\text { Muito } \\
\text { Alto }\end{array}$ \\
\hline 19 & Apoio da alta gerência & & & & $x$ & & \\
\hline 19 & Boa comunicação & & & & $\mathrm{x}$ & & \\
\hline 19 & Complexidade do projeto & & & & $\mathrm{x}$ & & \\
\hline 19 & $\begin{array}{l}\text { Controle/ Monitoramento } \\
\text { Efetivo }\end{array}$ & & & & $\mathrm{x}$ & & \\
\hline 19 & Envolvimento do cliente & & & & & $\mathrm{x}$ & \\
\hline 19 & Equipe qualificada & & & & & & $\mathrm{x}$ \\
\hline 19 & Gestor de projetos competente & & & & & $x$ & \\
\hline 19 & Objetivos claros e realistas & & & & & & $\mathrm{x}$ \\
\hline 19 & Orçamento adequado & & & & & & $\mathrm{x}$ \\
\hline 19 & Planejamento & & & & & $\mathrm{x}$ & \\
\hline 19 & Recursos suficientes & & & & & & $\mathrm{x}$ \\
\hline 20 & Apoio da alta gerência & & & & $\mathrm{x}$ & & \\
\hline 20 & Boa comunicação & & & & & & $\mathrm{x}$ \\
\hline 20 & Complexidade do projeto & & & & & $\mathrm{x}$ & \\
\hline 20 & $\begin{array}{l}\text { Controle/ Monitoramento } \\
\text { Efetivo }\end{array}$ & & & & & & $\mathrm{x}$ \\
\hline 20 & Envolvimento do cliente & & & & & & $x$ \\
\hline 20 & Equipe qualificada & & & & & & $x$ \\
\hline 20 & Gestor de projetos competente & & & & & & $\mathrm{x}$ \\
\hline 20 & Objetivos claros e realistas & & & & & & $\mathrm{x}$ \\
\hline 20 & Orçamento adequado & & & & & $x$ & \\
\hline 20 & Planejamento & & & & & & $x$ \\
\hline 20 & Recursos suficientes & & & & & $\mathrm{x}$ & \\
\hline 21 & Apoio da alta gerência & & & & & & $\mathrm{x}$ \\
\hline 21 & Boa comunicação & & & & & $x$ & \\
\hline 21 & Complexidade do projeto & & & & $\mathrm{x}$ & & \\
\hline 21 & $\begin{array}{l}\text { Controle/ Monitoramento } \\
\text { Efetivo }\end{array}$ & & & & & $\mathrm{x}$ & \\
\hline 21 & Envolvimento do cliente & & & & & $\mathrm{x}$ & \\
\hline 21 & Equipe qualificada & & & & & $x$ & \\
\hline 21 & Gestor de projetos competente & & & & & $x$ & \\
\hline 21 & Objetivos claros e realistas & & & & & $\mathrm{x}$ & \\
\hline 21 & Orçamento adequado & & & & & $x$ & \\
\hline 21 & Planejamento & & & & & & $\mathrm{x}$ \\
\hline 21 & Recursos suficientes & & & & & & $\mathrm{x}$ \\
\hline
\end{tabular}

Tabela 16 - Resultados da pesquisa de campo - projetos avaliados como sucesso - projetos 19 ao 21 


\begin{tabular}{|c|c|c|c|c|c|c|c|}
\hline Projeto & Fator crítico de sucesso & Nenhum & $\begin{array}{l}\text { Muito } \\
\text { Baixo }\end{array}$ & Baixo & Moderado & Alto & $\begin{array}{l}\text { Muito } \\
\text { Alto }\end{array}$ \\
\hline 22 & Apoio da alta gerência & & & & $x$ & & \\
\hline 22 & Boa comunicação & & & & & & $\mathrm{x}$ \\
\hline 22 & Complexidade do projeto & & & & $x$ & & \\
\hline 22 & $\begin{array}{l}\text { Controle/ Monitoramento } \\
\text { Efetivo }\end{array}$ & & & & & $x$ & \\
\hline 22 & Envolvimento do cliente & & & & & & $\mathrm{x}$ \\
\hline 22 & Equipe qualificada & & & & & $x$ & \\
\hline 22 & Gestor de projetos competente & & & & & $x$ & \\
\hline 22 & Objetivos claros e realistas & & & & & $x$ & \\
\hline 22 & Orçamento adequado & & & $x$ & & & \\
\hline 22 & Planejamento & & & $x$ & & & \\
\hline 22 & Recursos suficientes & & & & $x$ & & \\
\hline 23 & Apoio da alta gerência & & & & & & $\mathrm{x}$ \\
\hline 23 & Boa comunicação & & & & & & $\mathrm{x}$ \\
\hline 23 & Complexidade do projeto & & $\mathrm{x}$ & & & & \\
\hline 23 & $\begin{array}{l}\text { Controle/ Monitoramento } \\
\text { Efetivo }\end{array}$ & & & & & & $x$ \\
\hline 23 & Envolvimento do cliente & & & & & & $\mathrm{x}$ \\
\hline 23 & Equipe qualificada & & & & & $x$ & \\
\hline 23 & Gestor de projetos competente & & & & & $x$ & \\
\hline 23 & Objetivos claros e realistas & & & & & & $x$ \\
\hline 23 & Orçamento adequado & & & & & & $\mathrm{x}$ \\
\hline 23 & Planejamento & & & & & & $x$ \\
\hline 23 & Recursos suficientes & & & & & $x$ & \\
\hline 24 & Apoio da alta gerência & & $x$ & & & & \\
\hline 24 & Boa comunicação & & & & & & $\mathrm{x}$ \\
\hline 24 & Complexidade do projeto & & & & & $x$ & \\
\hline 24 & $\begin{array}{l}\text { Controle/ Monitoramento } \\
\text { Efetivo }\end{array}$ & & & & & $x$ & \\
\hline 24 & Envolvimento do cliente & & & & & $x$ & \\
\hline 24 & Equipe qualificada & & $x$ & & & & \\
\hline 24 & Gestor de projetos competente & & & & & $x$ & \\
\hline 24 & Objetivos claros e realistas & & & & & & $\mathrm{x}$ \\
\hline 24 & Orçamento adequado & & & & & $x$ & \\
\hline 24 & Planejamento & & & & & & $\mathrm{x}$ \\
\hline 24 & Recursos suficientes & & & & & $\mathrm{x}$ & \\
\hline
\end{tabular}

Tabela 17 - Resultados da pesquisa de campo - projetos avaliados como sucesso - projetos 22 ao 24 


\begin{tabular}{|c|c|c|c|c|c|c|c|}
\hline Projeto & Fator crítico de sucesso & Nenhum & $\begin{array}{l}\text { Muito } \\
\text { Baixo }\end{array}$ & Baixo & Moderado & Alto & $\begin{array}{l}\text { Muito } \\
\text { Alto }\end{array}$ \\
\hline 25 & Apoio da alta gerência & & & & & & $x$ \\
\hline 25 & Boa comunicação & & & & & & $x$ \\
\hline 25 & Complexidade do projeto & & & & & $x$ & \\
\hline 25 & $\begin{array}{l}\text { Controle/ Monitoramento } \\
\text { Efetivo }\end{array}$ & & & & & $x$ & \\
\hline 25 & Envolvimento do cliente & & & & & $x$ & \\
\hline 25 & Equipe qualificada & & & & & & $x$ \\
\hline 25 & Gestor de projetos competente & & & & & & $x$ \\
\hline 25 & Objetivos claros e realistas & & & & & & $x$ \\
\hline 25 & Orçamento adequado & & & & & & $x$ \\
\hline 25 & Planejamento & & & & & $x$ & \\
\hline 25 & Recursos suficientes & & & & & & $x$ \\
\hline 26 & Apoio da alta gerência & & & & & & $x$ \\
\hline 26 & Boa comunicação & & & & $x$ & & \\
\hline 26 & Complexidade do projeto & & & & $x$ & & \\
\hline 26 & $\begin{array}{l}\text { Controle/ Monitoramento } \\
\text { Efetivo }\end{array}$ & & & & & & $\mathrm{x}$ \\
\hline 26 & Envolvimento do cliente & & & $x$ & & & \\
\hline 26 & Equipe qualificada & & & & & $x$ & \\
\hline 26 & Gestor de projetos competente & & & & & $x$ & \\
\hline 26 & Objetivos claros e realistas & & & & & $x$ & \\
\hline 26 & Orçamento adequado & $x$ & & & & & \\
\hline 26 & Planejamento & & & $x$ & & & \\
\hline 26 & Recursos suficientes & & & & & & $x$ \\
\hline
\end{tabular}

Tabela 18 - Resultados da pesquisa de campo - projetos avaliados como sucesso - projetos 25 ao 26 


\section{Apêndice C - Resultados da pesquisa de campo: projetos avaliados como falha}

\begin{tabular}{|c|c|c|c|c|c|c|c|}
\hline Projeto & Fator crítico de sucesso & Nenhum & $\begin{array}{l}\text { Muito } \\
\text { Baixo }\end{array}$ & Baixo & Moderado & Alto & $\begin{array}{l}\text { Muito } \\
\text { Alto }\end{array}$ \\
\hline 27 & Apoio da alta gerência & $x$ & & & & & \\
\hline 27 & Boa comunicação & & & $x$ & & & \\
\hline 27 & Complexidade do projeto & $\mathrm{x}$ & & & & & \\
\hline 27 & $\begin{array}{l}\text { Controle/ Monitoramento } \\
\text { Efetivo }\end{array}$ & & & $x$ & & & \\
\hline 27 & Envolvimento do cliente & & $x$ & & & & \\
\hline 27 & Equipe qualificada & & $x$ & & & & \\
\hline 27 & Gestor de projetos competente & & $x$ & & & & \\
\hline 27 & Objetivos claros e realistas & & & & $x$ & & \\
\hline 27 & Orçamento adequado & & & & & $x$ & \\
\hline 27 & Planejamento & & & $x$ & & & \\
\hline 27 & Recursos suficientes & & & & $x$ & & \\
\hline 28 & Apoio da alta gerência & & & $x$ & & & \\
\hline 28 & Boa comunicação & & & $x$ & & & \\
\hline 28 & Complexidade do projeto & & $x$ & & & & \\
\hline 28 & $\begin{array}{l}\text { Controle/ Monitoramento } \\
\text { Efetivo }\end{array}$ & & & $x$ & & & \\
\hline 28 & Envolvimento do cliente & & & $x$ & & & \\
\hline 28 & Equipe qualificada & & $x$ & & & & \\
\hline 28 & Gestor de projetos competente & & $x$ & & & & \\
\hline 28 & Objetivos claros e realistas & $x$ & & & & & \\
\hline 28 & Orçamento adequado & & & & & $x$ & \\
\hline 28 & Planejamento & & $x$ & & & & \\
\hline 28 & Recursos suficientes & $x$ & & & & & \\
\hline 29 & Apoio da alta gerência & $x$ & & & & & \\
\hline 29 & Boa comunicação & $x$ & & & & & \\
\hline 29 & Complexidade do projeto & & $x$ & & & & \\
\hline 29 & $\begin{array}{l}\text { Controle/ Monitoramento } \\
\text { Efetivo }\end{array}$ & & & $x$ & & & \\
\hline 29 & Envolvimento do cliente & & & $x$ & & & \\
\hline 29 & Equipe qualificada & & & $x$ & & & \\
\hline 29 & Gestor de projetos competente & & & $x$ & & & \\
\hline 29 & Objetivos claros e realistas & & $x$ & & & & \\
\hline 29 & Orçamento adequado & & & & & & $x$ \\
\hline 29 & Planejamento & $\mathrm{x}$ & & & & & \\
\hline 29 & Recursos suficientes & & $x$ & & & & \\
\hline
\end{tabular}

Tabela 19 - Resultados da pesquisa de campo - projetos avaliados como falha - projetos 27 ao 29 


\begin{tabular}{|c|c|c|c|c|c|c|c|}
\hline Projeto & Fator crítico de sucesso & Nenhum & $\begin{array}{l}\text { Muito } \\
\text { Baixo }\end{array}$ & Baixo & Moderado & Alto & $\begin{array}{c}\text { Muito } \\
\text { Alto }\end{array}$ \\
\hline 30 & Apoio da alta gerência & & & $x$ & & & \\
\hline 30 & Boa comunicação & & & & $x$ & & \\
\hline 30 & Complexidade do projeto & & & $x$ & & & \\
\hline 30 & $\begin{array}{l}\text { Controle/ Monitoramento } \\
\text { Efetivo }\end{array}$ & $\mathrm{x}$ & & & & & \\
\hline 30 & Envolvimento do cliente & & & $x$ & & & \\
\hline 30 & Equipe qualificada & $x$ & & & & & \\
\hline 30 & Gestor de projetos competente & $x$ & & & & & \\
\hline 30 & Objetivos claros e realistas & & & & $\mathrm{x}$ & & \\
\hline 30 & Orçamento adequado & $x$ & & & & & \\
\hline 30 & Planejamento & & & & $x$ & & \\
\hline 30 & Recursos suficientes & & & $\mathrm{x}$ & & & \\
\hline 31 & Apoio da alta gerência & & & $\mathrm{x}$ & & & \\
\hline 31 & Boa comunicação & & $x$ & & & & \\
\hline 31 & Complexidade do projeto & $x$ & & & & & \\
\hline 31 & $\begin{array}{l}\text { Controle/ Monitoramento } \\
\text { Efetivo }\end{array}$ & & $\mathrm{x}$ & & & & \\
\hline 31 & Envolvimento do cliente & & $x$ & & & & \\
\hline 31 & Equipe qualificada & & $\mathrm{x}$ & & & & \\
\hline 31 & Gestor de projetos competente & & & $x$ & & & \\
\hline 31 & Objetivos claros e realistas & $x$ & & & & & \\
\hline 31 & Orçamento adequado & & $\mathrm{x}$ & & & & \\
\hline 31 & Planejamento & $x$ & & & & & \\
\hline 31 & Recursos suficientes & & & & $\mathrm{x}$ & & \\
\hline 32 & Apoio da alta gerência & $x$ & & & & & \\
\hline 32 & Boa comunicação & & & & & $x$ & \\
\hline 32 & Complexidade do projeto & $x$ & & & & & \\
\hline 32 & $\begin{array}{l}\text { Controle/ Monitoramento } \\
\text { Efetivo }\end{array}$ & & & & & $x$ & \\
\hline 32 & Envolvimento do cliente & & & & & $x$ & \\
\hline 32 & Equipe qualificada & $x$ & & & & & \\
\hline 32 & Gestor de projetos competente & $\mathrm{x}$ & & & & & \\
\hline 32 & Objetivos claros e realistas & $x$ & & & & & \\
\hline 32 & Orçamento adequado & $x$ & & & & & \\
\hline 32 & Planejamento & & & & & $x$ & \\
\hline 32 & Recursos suficientes & $\mathrm{x}$ & & & & & \\
\hline
\end{tabular}

Tabela 20 - Resultados da pesquisa de campo - projetos avaliados como falha - projetos 30 ao 32 


\begin{tabular}{|c|c|c|c|c|c|c|c|}
\hline Projeto & Fator crítico de sucesso & Nenhum & $\begin{array}{l}\text { Muito } \\
\text { Baixo }\end{array}$ & Baixo & Moderado & Alto & $\begin{array}{l}\text { Muito } \\
\text { Alto }\end{array}$ \\
\hline 33 & Apoio da alta gerência & $x$ & & & & & \\
\hline 33 & Boa comunicação & & $x$ & & & & \\
\hline 33 & Complexidade do projeto & & & $x$ & & & \\
\hline 33 & $\begin{array}{l}\text { Controle/ Monitoramento } \\
\text { Efetivo }\end{array}$ & & & $\mathrm{x}$ & & & \\
\hline 33 & Envolvimento do cliente & & & & & $x$ & \\
\hline 33 & Equipe qualificada & $x$ & & & & & \\
\hline 33 & Gestor de projetos competente & $x$ & & & & & \\
\hline 33 & Objetivos claros e realistas & $x$ & & & & & \\
\hline 33 & Orçamento adequado & $x$ & & & & & \\
\hline 33 & Planejamento & & & & & $x$ & \\
\hline 33 & Recursos suficientes & $x$ & & & & & \\
\hline 34 & Apoio da alta gerência & & & & & $x$ & \\
\hline 34 & Boa comunicação & & $x$ & & & & \\
\hline 34 & Complexidade do projeto & & $x$ & & & & \\
\hline 34 & $\begin{array}{l}\text { Controle/ Monitoramento } \\
\text { Efetivo }\end{array}$ & & & $x$ & & & \\
\hline 34 & Envolvimento do cliente & & & & $x$ & & \\
\hline 34 & Equipe qualificada & $x$ & & & & & \\
\hline 34 & Gestor de projetos competente & & & & & $x$ & \\
\hline 34 & Objetivos claros e realistas & $x$ & & & & & \\
\hline 34 & Orçamento adequado & & & & & $x$ & \\
\hline 34 & Planejamento & $x$ & & & & & \\
\hline 34 & Recursos suficientes & & $x$ & & & & \\
\hline 35 & Apoio da alta gerência & & & & & $x$ & \\
\hline 35 & Boa comunicação & & & & & $x$ & \\
\hline 35 & Complexidade do projeto & $x$ & & & & & \\
\hline 35 & $\begin{array}{l}\text { Controle/ Monitoramento } \\
\text { Efetivo }\end{array}$ & & $x$ & & & & \\
\hline 35 & Envolvimento do cliente & & & $x$ & & & \\
\hline 35 & Equipe qualificada & $x$ & & & & & \\
\hline 35 & Gestor de projetos competente & $x$ & & & & & \\
\hline 35 & Objetivos claros e realistas & & $x$ & & & & \\
\hline 35 & Orçamento adequado & & & & & $x$ & \\
\hline 35 & Planejamento & & & & & $x$ & \\
\hline 35 & Recursos suficientes & $x$ & & & & & \\
\hline
\end{tabular}

Tabela 21 - Resultados da pesquisa de campo - projetos avaliados como falha - projetos 33 ao 35 


\begin{tabular}{|c|c|c|c|c|c|c|c|}
\hline Projeto & Fator crítico de sucesso & Nenhum & $\begin{array}{l}\text { Muito } \\
\text { Baixo }\end{array}$ & Baixo & Moderado & Alto & $\begin{array}{c}\text { Muito } \\
\text { Alto }\end{array}$ \\
\hline 36 & Apoio da alta gerência & & & & & $x$ & \\
\hline 36 & Boa comunicação & & & & $\mathrm{x}$ & & \\
\hline 36 & Complexidade do projeto & & & $x$ & & & \\
\hline 36 & $\begin{array}{l}\text { Controle/ Monitoramento } \\
\text { Efetivo }\end{array}$ & $\mathrm{x}$ & & & & & \\
\hline 36 & Envolvimento do cliente & & & & $x$ & & \\
\hline 36 & Equipe qualificada & & & $x$ & & & \\
\hline 36 & Gestor de projetos competente & & & $x$ & & & \\
\hline 36 & Objetivos claros e realistas & $\mathrm{x}$ & & & & & \\
\hline 36 & Orçamento adequado & & & & & $\mathrm{x}$ & \\
\hline 36 & Planejamento & $\mathrm{x}$ & & & & & \\
\hline 36 & Recursos suficientes & $x$ & & & & & \\
\hline 37 & Apoio da alta gerência & & & $\mathrm{x}$ & & & \\
\hline 37 & Boa comunicação & & & $x$ & & & \\
\hline 37 & Complexidade do projeto & & $x$ & & & & \\
\hline 37 & $\begin{array}{l}\text { Controle/ Monitoramento } \\
\text { Efetivo }\end{array}$ & & & $\mathrm{x}$ & & & \\
\hline 37 & Envolvimento do cliente & & & $x$ & & & \\
\hline 37 & Equipe qualificada & & $x$ & & & & \\
\hline 37 & Gestor de projetos competente & & $\mathrm{x}$ & & & & \\
\hline 37 & Objetivos claros e realistas & $x$ & & & & & \\
\hline 37 & Orçamento adequado & & $x$ & & & & \\
\hline 37 & Planejamento & & $\mathrm{x}$ & & & & \\
\hline 37 & Recursos suficientes & $x$ & & & & & \\
\hline 38 & Apoio da alta gerência & & & & & $x$ & \\
\hline 38 & Boa comunicação & & & & $x$ & & \\
\hline 38 & Complexidade do projeto & & & $x$ & & & \\
\hline 38 & $\begin{array}{l}\text { Controle/ Monitoramento } \\
\text { Efetivo }\end{array}$ & $x$ & & & & & \\
\hline 38 & Envolvimento do cliente & & & & $\mathrm{x}$ & & \\
\hline 38 & Equipe qualificada & & & $x$ & & & \\
\hline 38 & Gestor de projetos competente & & & $x$ & & & \\
\hline 38 & Objetivos claros e realistas & $x$ & & & & & \\
\hline 38 & Orçamento adequado & & $x$ & & & & \\
\hline 38 & Planejamento & $x$ & & & & & \\
\hline 38 & Recursos suficientes & $\mathrm{x}$ & & & & & \\
\hline
\end{tabular}

Tabela 22 - Resultados da pesquisa de campo - projetos avaliados como falha - projetos 36 ao 38 


\begin{tabular}{|c|c|c|c|c|c|c|c|}
\hline Projeto & Fator crítico de sucesso & Nenhum & $\begin{array}{l}\text { Muito } \\
\text { Baixo }\end{array}$ & Baixo & Moderado & Alto & $\begin{array}{c}\text { Muito } \\
\text { Alto }\end{array}$ \\
\hline 39 & Apoio da alta gerência & & & $x$ & & & \\
\hline 39 & Boa comunicação & & & & $x$ & & \\
\hline 39 & Complexidade do projeto & & & $x$ & & & \\
\hline 39 & $\begin{array}{l}\text { Controle/ Monitoramento } \\
\text { Efetivo }\end{array}$ & $\mathrm{x}$ & & & & & \\
\hline 39 & Envolvimento do cliente & & & $x$ & & & \\
\hline 39 & Equipe qualificada & $x$ & & & & & \\
\hline 39 & Gestor de projetos competente & $x$ & & & & & \\
\hline 39 & Objetivos claros e realistas & & & & $x$ & & \\
\hline 39 & Orçamento adequado & $x$ & & & & & \\
\hline 39 & Planejamento & & & & $x$ & & \\
\hline 39 & Recursos suficientes & & & $x$ & & & \\
\hline 40 & Apoio da alta gerência & & & & & $\mathrm{x}$ & \\
\hline 40 & Boa comunicação & & & & & $x$ & \\
\hline 40 & Complexidade do projeto & $x$ & & & & & \\
\hline 40 & $\begin{array}{l}\text { Controle/ Monitoramento } \\
\text { Efetivo }\end{array}$ & & $\mathrm{x}$ & & & & \\
\hline 40 & Envolvimento do cliente & & & $x$ & & & \\
\hline 40 & Equipe qualificada & $x$ & & & & & \\
\hline 40 & Gestor de projetos competente & $x$ & & & & & \\
\hline 40 & Objetivos claros e realistas & & $x$ & & & & \\
\hline 40 & Orçamento adequado & & $x$ & & & & \\
\hline 40 & Planejamento & & & & & $x$ & \\
\hline 40 & Recursos suficientes & $x$ & & & & & \\
\hline 41 & Apoio da alta gerência & & $x$ & & & & \\
\hline 41 & Boa comunicação & & & & & $x$ & \\
\hline 41 & Complexidade do projeto & & & $x$ & & & \\
\hline 41 & $\begin{array}{l}\text { Controle/ Monitoramento } \\
\text { Efetivo }\end{array}$ & & $\mathrm{x}$ & & & & \\
\hline 41 & Envolvimento do cliente & & $\mathrm{x}$ & & & & \\
\hline 41 & Equipe qualificada & & $x$ & & & & \\
\hline 41 & Gestor de projetos competente & & & & & $x$ & \\
\hline 41 & Objetivos claros e realistas & & & & & $\mathrm{x}$ & \\
\hline 41 & Orçamento adequado & & & & & $x$ & \\
\hline 41 & Planejamento & & & & & $x$ & \\
\hline 41 & Recursos suficientes & & & & & $x$ & \\
\hline
\end{tabular}

Tabela 23 - Resultados da pesquisa de campo - projetos avaliados como falha - projetos 39 ao 41 


\begin{tabular}{|c|c|c|c|c|c|c|c|}
\hline Projeto & Fator crítico de sucesso & Nenhum & $\begin{array}{c}\text { Muito } \\
\text { Baixo }\end{array}$ & Baixo & Moderado & Alto & $\begin{array}{c}\text { Muito } \\
\text { Alto }\end{array}$ \\
\hline 42 & Apoio da alta gerência & & $x$ & & & & \\
\hline 42 & Boa comunicação & & & & & $x$ & \\
\hline 42 & Complexidade do projeto & & & $x$ & & & \\
\hline 42 & $\begin{array}{l}\text { Controle/ Monitoramento } \\
\text { Efetivo }\end{array}$ & & $x$ & & & & \\
\hline 42 & Envolvimento do cliente & & $x$ & & & & \\
\hline 42 & Equipe qualificada & & $\mathrm{x}$ & & & & \\
\hline 42 & Gestor de projetos competente & & & & & $x$ & \\
\hline 42 & Objetivos claros e realistas & & & & & $\mathrm{x}$ & \\
\hline 42 & Orçamento adequado & & & & & $x$ & \\
\hline 42 & Planejamento & & & & & $x$ & \\
\hline 42 & Recursos suficientes & & & & & $x$ & \\
\hline 43 & Apoio da alta gerência & & & $x$ & & & \\
\hline 43 & Boa comunicação & & & & $x$ & & \\
\hline 43 & Complexidade do projeto & $x$ & & & & & \\
\hline 43 & $\begin{array}{l}\text { Controle/ Monitoramento } \\
\text { Efetivo }\end{array}$ & & & $x$ & & & \\
\hline 43 & Envolvimento do cliente & & & & & $x$ & \\
\hline 43 & Equipe qualificada & & $x$ & & & & \\
\hline 43 & Gestor de projetos competente & $x$ & & & & & \\
\hline 43 & Objetivos claros e realistas & & & $x$ & & & \\
\hline 43 & Orçamento adequado & & & & & & $x$ \\
\hline 43 & Planejamento & $x$ & & & & & \\
\hline 43 & Recursos suficientes & & & & $\mathrm{x}$ & & \\
\hline
\end{tabular}

Tabela 24 - Resultados da pesquisa de campo - projetos avaliados como sucesso - projetos 42 ao 43 